\title{
La configuración de los órganos unipersonales en la reforma del Régimen Local
}

\author{
Federico A. Castillo Blanco \\ Profesor Titular de Derecho Administrativo \\ Universidad de Granada
}

Sumario: I. INTRODUCCIÓN. 1. Una breve reflexión histórica sobre los órganos unipersonales en el Gobierno local. 2. Las decisiones de la Constitución sobre los órganos unipersonales de gobierno en la esfera local. 3. Los elementos de tensión y cambio para una perspectiva más gerencial de los órganos unipersonales existentes en el Gobierno local. II. LOS ÓRGANOS UNIPERSONALES EN EL GOBIERNO LOCAL Y EN SU RELACIÓN CON OTROS ÓRGANOS. III. LAS ATRIBUCIONES DE COMPETENCIAS A LOS ÓRGANOS UNIPERSONALES EN CUANTO PRESIDENTES DEL ENTE PÚBLICO. IV. LAS ATRIBUCIONES DE LOS ÓRGANOS UNIPERSONALES EN CUANTO PRESIDENTES DE LOS ÓRGANOS COLEGIADOS. V. LAS ATRIBUCIONES DE LOS ÓRGANOS UNIPERSONALES COMO TITULARES DEL ÓRGANO DIRECTOR ADMINISTRATIVO Y GUBERNATIVO DEL MUNICIPIO Y DE LA PROVINCIA. VI. CONCLUSIONES.

\section{INTRODUCCIÓN}

\section{Una breve reflexión histórica sobre los órganos unipersonales en el Gobierno local}

El estudio de la figura del Alcalde en nuestra legislación histórica, al menos en aquella que se inicia a partir del siglo XIX — sin perjuicio de que en el Antiguo Régimen también se encuentran rastros de las señas de identidad de esta figura--, pone de relieve que la configuración actual de la Alcaldía no ha sido fruto, sin perjuicio de su necesaria actualización al texto constitucional de 1978, de la definición de un modelo teórico más o menos valido, sino que, mucho más allá, sus rasgos definidores esenciales responden a una serie de debates subsistentes en los dos últimos siglos que han terminado por verter y decantar la actual planta municipal ' ${ }^{1}$. Di-

\footnotetext{
1 L. Morell Ocaña, La autonomía local, Edit. Civitas, Madrid, 1988, p. 548, expone que «... en la propia fórmula gaditana aparecen como encapsulados los tres grandes interrogantes sobre los que, en cada trance de nuestro constitucionalismo, se vuelve a poner en cuestión el carácter del Alcalde. Una y otra vez en la azarosa historia de nuestro régimen local contemporáneo, se plantean estos tres dilemas: $10^{\circ} \mathrm{Si}$ el Alcalde ha de encontrar su confianza en la base, en la vecindad, o en el poder del Estado. 2. ${ }^{\circ} \mathrm{Si}$ se está ante una magistratura municipal o, por el contrario, ante un órgano del Estado incrustado en el municipio. $3 .^{\circ} \mathrm{Si}$ ha de encarnar un liderazgo representativo o simplemente basta con exigirle una capacidad administrativa de gestión».
} 
cho aspecto no ha pasado inadvertido a la doctrina que ha realizado multitud de estudios sobre la figura y ha puesto de relieve dicha considera ción ${ }^{2}$, así como la existencia de variados modelos, al menos dos principales (correspondientes a los períodos conservadores y liberales), que progresivamente han ido modelando las principales características de la institución de la Alcaldía.

Como ha sido puesto de manifiesto en los estudios históricos que de ello se han ocupado, se inicia el siglo XIX con la conjunción en la figura de éste de una mescolanza de funciones ejecutivas, gubernativas y judiciales fundamentalmente, a lo que hay que añadir la condición de órgano estatal que le era atribuida. Así luce en la Constitución de Cádiz y dichos rasgos, en mayor o menor medida, permanecerán subsistentes en buena parte de ese siglo. El Alcalde, expone ZAFRA, aparece caracterizado como una institución gubernativa, subordinada al poder ejecutivo y reducida su capacidad de iniciativa a las cuestiones que no excedieran los límites del municipio ${ }^{3}$.

De otro lado, si las funciones judiciales persisten en éste, como consecuencia de su consideración en períodos anteriores y sólo progresivamente irán difuminándose a medida que transcurra el tiempo ${ }^{4}$, su conexión con la organización estatal se debe al principio de unidad del poder ejecutivo definido en el propio texto constitucional y en las funciones gubernativas que éste ejerce ${ }^{5}$, siendo en este último caso la separación, bien es verdad, más lenta y laboriosa que en el supuesto anterior.

\footnotetext{
${ }^{2}$ Entre otros muchos pueden citarse E. GarCí DE ENTERRIA, «Turgot y los orígenes del municipalismo moderno», RAP n. ${ }^{\circ} 33,1960$; C. CARRASCo Canals, «El municipio en la Administración Española en el S. XIX», REALA n. ${ }^{\circ} 173$, 1972; J. I. Morillo-Velarde Pérez, El Alcalde en la Administración española, Edit. Instituto García Oviedo, Sevilla, 1977; J. A. Santamaria Pastor, «Estudio Preliminar» a Dirección teórico-práctica de Alcaldes constitucionales, IEAL, Madrid, 1979; L. MORELl OCAÑA, «La figura del Alcalde desde la Constitución de Cádiz hasta el canovismo", REDA n. ${ }^{\circ} 33,1982$ y El Régimen Local Español, Edit. Civitas, Madrid, 1988, esta última obra de imprescindible consulta; J. GARCíA FERNÁNDEZ, El origen del municipio constitucional, Edit. IEAL, Madrid, 1983; A. MARTiNEz MARIN, La representatividad municipal española. Historia legislativa y régimen vigente, Secretariado de Publicaciones de la Universidad de Murcia, 1989; y C. Guirado Cid, El Alcalde en la legislación española, Edit. Trivium, Madrid, 1991.
}

${ }^{3}$ M. Zafra Victor, «Estudio preliminan» al libro Dirección Teórico Práctica de Alcaldes Constitucionales, Edit. CEMCI, Granada, 1993, p. 33.

${ }^{4}$ Desaparecerán en forma definitiva con la Ley Municipal de 5 de julio de 1856, que atribuirá el último reducto de funciones judiciales en manos del Alcalde a los Jueces de Paz.

${ }^{5}$ Como ha puesto de relieve E. GarCí DE ENTERRÍA, La Administración española, Alianza Editorial, Madrid, 1975, p. 71: «La construcción napoleónica es la esencial, la que alcanzó una suerte definitiva e inconmovible, y consistió nada más que en establecer esa articulación inexistente entre los entes locales y el Estado por medio de una técnica organizativa tan perfectamente simple como 
A este periodo inicial, comprensivo del primer tercio de siglo, y prácticamente hasta el Estatuto Municipal de 1924, le siguen dos modelos que, como tantas otras cosas en el siglo XIX, irán alternándose según el perfil progresista o moderado de los sucesivos regímenes y que se diferencian fundamentalmente, como característica distintiva y definitoria frente al alternativo, en la forma de elección del Alcalde ${ }^{6}$. Sin embargo, y por encima de ese tejer y destejer que caracteriza a todo este período, la consolidación progresiva en las distintas leyes municipales que se suceden del Alcalde en su consideración de órgano local, separación del poder central, robustecimiento de la vocación ejecutiva y de gestión de este órgano municipal, incremento de las garantías en el ejercicio de sus funciones, etcétera, son hechos incontrovertibles que ponen de relieve la superación, lenta pero imparable, por el municipio de su nivel de dependencia del poder central y su autoafirmación como esfera de gobierno propia dirigida a la satisfacción de los intereses locales.

El Estatuto Municipal de 1924 afirmará la figura del Alcalde, incidiendo básicamente en la independencia y capacidad de gestión de éste, de forma tal que ya no habrá de responder políticamente frente al poder central salvo en el ejercicio de aquellas competencias delegadas a éste.

El breve paréntesis republicano se salda, a grandes rasgos, en el debe y en el haber con una mayor democratización de la institución, pero con el retorno, tal vez explicable en la enorme convulsión político-social en dichas fechas, de la posibilidad de suspensión gubernativa de éste por parte de las instituciones centrales.

El período que se inicia tras la guerra civil, y de acuerdo con los postulados del régimen que lo inspiraban, abre un paréntesis en esta evolución que se plasma en un retroceso en la democratización de las instituciones locales y una dependencia pseudojerárquica del Alcalde respecto de las autoridades centrales que controlarán su nombramiento y cese, lo que tiene como consecuencia inmediata una pérdida de vigor y representatividad de la figura y de las propias instituciones locales como garantes de los intereses locales; paréntesis que no termina de cerrarse — a pesar de la

efectivamente luminosa y genial: la técnica de reservar la esfera de la acción a una línea de agentes monocráticos o individuales ligados precisamente por el vínculo de la jerarquía desplazando lateralmente las corporaciones colegiales a un simple papel de deliberación y de consejo.»

${ }^{6}$ Es decir, según que se postule la elección del Alcalde o el denominado sistema de las dos confianzas: el Estado designa al Alcalde de entre los concejales, elegidos de forma previa por el electorado. La Ley municipal de 1870 introducirá, por vez primera, el sistema electivo indirecto que es el vigente en la actualidad, aunque de escasa duración pues sólo permanecerá hasta la Restauración. 
Ley de Régimen Local de 1975- hasta la promulgación, tras la STC de 2 de febrero de 1981 y las consideraciones de constitucionalidad por ésta realizadas sobre las leyes municipales anteriores, de la Ley 40/1981, de 28 de octubre, y más decisivamente por la aprobación de la Ley $7 / 1985$, de 2 de abril, Reguladora de las Bases de Régimen Local, que finalmente configura una Alcaldía, heredera, si bien sólo en cierta medida, de ese desarrollo histórico y de las tradiciones municipales españolas que la enmarcan, pero que intenta responder a los parámetros constitucionales a los que a continuación nos referiremos, con la consiguiente democratización de su elección y la plena consideración de éste como un órgano local dirigido a la preservación, defensa y gestión del interés local que rompe, aunque sólo en cierto sentido, lo que MORELL ha denominado bicefalia formal entre Alcalde y Ayuntamiento, en cuanto a las funciones ejecutivas, existente en la legislación anterior con un predominio del órgano unipersonal $?$.

Como puede comprobarse, y a pesar de la brevedad de las ideas expresadas, las sucesivas y numerosas reformas y contrarreformas mantienen una línea constante siempre dirigida en la dirección de robustecer la figura del Alcalde, en su consideración de órgano ejecutivo y gerencial de los intereses locales, lo que bien puede decirse ha sido una constante en la evolución de la figura ${ }^{8}$. El desprendimiento, en primer término, de las funciones judiciales que se aunaban a la figura; su progresiva independencia del poder central rompiendo el mito napoleónico de unidad del poder ejecutivo; el fortalecimiento de su capacidad de gestión, etc..., son notas que avalan la anterior conclusión. El siguiente capítulo en esta evolución viene constituido por la reforma de 1999, objeto del presente trabajo, que analizaremos a continuación, no, sin embargo, sin hacer de forma previa unas consideraciones sobre la figura de los órganos unipersonales en el gobierno provincial.

El caso del Presidente de la Diputación Provincial constituye, en sí mismo, y dado el propio origen de las instituciones provinciales, un supuesto distinto al del Alcalde. En efecto, como ha puesto de relieve MORELL, hasta la Ley de 1870 no se produce un proceso de diferenciación orgánica entre los órganos del Estado en la Provincia y la propia $\mathrm{Di}$ putación Provincial, a la que se asignan ya medios personales y materia-

\footnotetext{
${ }^{7}$ L. MORELL, El Régimen local..., op. cit., pp. 468 y ss.

${ }^{8}$ Idea que es mantenida por C. GuIrado CiD, «Aproximación al estudio de la Alcaldía a través de su evolución legislativa», $R E A L A$ n. $.^{\circ} 252,1991$, p. 880 , y puesta de relieve por MORELl en la obra ya citada al analizar los antecedentes legislativos, sobre todo a partir de 1945.
} 
les para el cumplimiento de sus funciones 9 ; proceso, sin embargo, que durante la Restauración se verá interrumpido con el fortalecimiento del Gobernador como vértice del poder ejecutivo de la Administración provincial y que no culminará hasta el Estatuto Provincial de 1925, que desligará definitivamente al Gobernador Civil de la Presidencia efectiva de dicha institución ${ }^{10}$.

Las leyes locales del régimen autocrático del General Franco vuelven a ligar al Gobernador Civil a las Diputaciones Provinciales en la medida que se le asigna un carácter de Presidente nato que se manifiesta, entre otras posibilidades, en la designación del Presidente efectivo que se intenta asuma sus funciones con carácter gerencial. Será la Ley $41 / 1975$, de 19 de noviembre, la que definivamente posibilite al Presidente de la Diputación alcanzar, de nuevo y en esta ocasión de forma definitiva, su autonomía orgánica respecto del Gobernador Civil.

La Constitución de 1978 marca, sin duda, un nuevo hito, pues si bien deja claro que el gobierno y la administración provincial se atribuirá a órganos representativos, no configura a las Diputaciones Provinciales sino como una posibilidad o alternativa para ello, a definir por el legislador estatal en la normativa básica. Por tanto, no existe un diseño ni unos requisitos previos constitucionales para el gobierno provincial salvo su naturaleza representativa y el respeto a la organización histórica de los territorios forales.

La legislación estatal de régimen local y electoral de 1985 optaron, salvando los derechos históricos y los regímenes insulares, por el modelo tradicional de las Diputaciones Provinciales, si bien estableciendo un

\footnotetext{
${ }^{9}$ L. Morell, El Régimen local..., op. cit., pp. 735 y ss., quien pone de relieve que el Gobiemo de la Provincia descansaba en dos órganos: la Diputación Provincial y el Jefe político (figura que, con el correr de los años, se constituirá en el Gobernador Civil). Las Diputaciones se debaten en todo ese periodo, que va desde la Constitución de 1812 hasta 1870 , entre su vocación de órganos representativos de carácter local y entre el carácter de prolongación del Poder ejecutivo central que pretende situarlas como puro instrumento de colaboración social, teniendo presente el modelo del Consejo General del Departamento que se había organizado en Francia del que, sin embargo, se aparta dada la condición electiva de sus miembros, pero al que se le asignan competencias propias. El Jefe politico, sobre todo en la etapa moderada, ejercerá un importante control sobre la actividad de éstas y, desde luego, su actividad administrativa será ejercida por éste que asume las funciones de Presidente de la Diputación. La Ley de 1870, no obstante profundizar en la distinción apuntada, sigue atribuyendo al Gobernador Civil las funciones de Presidente y órgano ejecutivo de la Diputación Provincial, a las que se unen las de Jefe de la Administración periférica del Estado.

10 De otro lado, la institución provincial sufre importantes cambios de carácter cualitativo: potenciación de las funciones de apoyo a los municipios con una pérdida de funciones de tutela; elección mixta, directa y corporativa entre concejales, para los diputados provinciales.
} 
modelo de representación indirecta con un sufragio de segundo grado entre los concejales electos de los partidos judiciales en atención a su población, dejando abierta la posibilidad de que éste adquiera el carácter de Delegado de la Administración autonómica en la provincia y asimilando el cargo de Presidente de la Diputación Provincial al del Alcalde en cuanto a su nombramiento, cese y funciones (si bien en el caso del Presidente de la Diputación Provincial parece más apropiado hablar de una elección de tercer grado). Aserto este último que nos permite afirmar, como en el caso del municipio, la opción de dicha legislación por el fortalecimiento del órgano unipersonal ${ }^{11}$.

\section{Las decisiones de la Constitución sobre los órganos unipersonales de Gobierno en la esfera local}

Los parámetros constitucionales establecidos en los pocos artículos que nuestra Constitución dedica al régimen local no ofrecen, en un primer acercamiento, una respuesta incontrovertible que, desde nuestro punto de vista, permiten variadas opciones en la organización munici pal ${ }^{12}$, y que han sido concretadas por la Ley Reguladora de Régimen Local y la Ley de Régimen Electoral que han operado, al respecto, como normas integrantes del bloque de constitucionalidad.

En este último sentido expresado, tanto podría haberse optado, si agrupamos en dos grandes grupos las estructuras ejecutivas existentes en la mayoría de los gobiernos locales occidentales, por dos modelos: un modelo monocrático en que la mayoría de las competencias ejecutivas y de dirección política corresponden al Alcalde, elegido por votación popular de modo directo o indirecto; o bien, formas colegiadas en que comités o comisiones asumen total o parcialmente las principales competencias ejecutivas, bien prescindiendo de la figura del Alcalde (posibilidad ésta de difícil admisión en nuestro sistema constitucional), bien compartiendo

\footnotetext{
"Señala, sin embargo, Morell que en el caso del Presidente de la Diputación Provincial se produce una ruptura con el régimen anterior, el consagrado en la Ley de Régimen Local de 1955, en que el Presidente aparecía como un órgano diferenciado de la Diputación, a la que gobernaba desde las facultades que el legislador le otorgaba. Y con el sistema establecido en la Ley de Elecciones Locales de 1978, en que el Presidente sólo tiene una función de dirección y presidencia de los órganos colegiados, ostentando exclusivamente las funciones ejecutivas que se le atribuyesen por el Pleno, op. cit., pp. 775 y 776 .

12 Efectivamente, el artículo $140.1 \mathrm{CE}$ establece que el gobierno y administración de los municipios corresponde a sus Ayuntamientos, integrados por los Alcaldes y Concejales. Los Concejales serán elegidos por los vecinos del municipio mediante sufragio universal, igual, libre, directo y secreto en la forma establecida por la Ley. Los Alcaldes serán elegidos por los Concejales o por los vecinos. La Ley regulará las condiciones en las que proceda el Concejo Abierto.
} 
las funciones de dirección política con éste o ia asambiea del municipio ${ }^{13}$.

No obstante, eso sí, algunas consecuencias es posible extraer de su configuración constitucional (art. $140 \mathrm{CE}$ ). La más decisiva, de acuerdo con ORTEGA, la constituye la de que el Alcalde es un órgano del Ayuntamiento y es éste el que asume la representación de la colectividad local y, en nombre de ella, el gobierno y administración del municipio y, por ello, ha de ser un órgano con sustantividad y competencias propias dentro del entramado institucional del municipio ${ }^{14}$. No cabe, por tanto, su supresión o su mera configuración como un órgano meramente representativo sin competencias de gestión y administración en las tareas municipales, dada la protección que la garantía institucional de la autonomía local otorga a este órgano. Más discutible resulta, sin embargo, su necesaria configuración como Presidente del órgano deliberante y de control que la legislación local le asigna y que admite, sin duda, otras posibilidades.

Distintas han de ser las conclusiones en el caso del Presidente de la Diputación Provincial, sobre todo si tenemos en cuenta las consideraciones ya efectuadas en el apartado anterior. En efecto, si como en el caso municipal, puede afirmarse la existencia en la provincia de una garantía institucional de su autonomía (STC 32/1981), no existen, sin embargo, previsiones específicas en cuanto al modelo de organización de la misma más allá de que inserta en dicha autonomía reconocida se encuentra la potestad de autoorganización. El artículo $141 \mathrm{CE}$ se limita a proclamar que su gobierno y administración autónoma corresponderá a las Diputaciones u otras Corporaciones de carácter representativo, no estableciendo ninguna previsión al respecto de la necesaria existencia de ningún órgano y dejando abierta, por tanto, diversas soluciones, aun más que en el caso municipal, posibles. De hecho, tanto en el caso vasco, como balear o canario su organización y gobierno se configuran, de acuerdo con lo prevenido en

\footnotetext{
13 Puede consultarse respecto al ejercicio del liderazgo local y los rasgos y características que lo distinguirían de otros niveles de gobierno el trabajo «Formas y estilos de liderazgo local» de A. NATERA, en el volumen colectivo El sistema político local: un nuevo escenario de gobierno, Universidad Carlos III y Boletin Oficial del Estado, Madrid, 1997, pp. 113 y ss. Diversos modelos pueden encontrarse, ceñidos al ámbito europeo, en Anuario del Gobierno Local, Madrid, 1996, pp. 722 y ss. y en la monografia de P. Bensusan MARTín, El concejal en el ordenamiento juridico español, Editorial Comares, Granada, 1999, pp. 205 y ss., que resume, a grandes rasgos, la existencia de un órgano deliberante electivo, una Comisión reducida de carácter ejecutivo y un órgano unipersonal de carácter ejecutivo que asume la presidencia de ambos, electo, en la mayoría de los casos, por el órgano deliberante.

14 L. ORTEGA, «El Alcalde como elemento de la organización municipal», $D A$ n. ${ }^{0} 228$, 1991, pp. 46 y ss.
} 
sus Estatutos de Autonomía y en la legislación reguladora de régimen lo$\mathrm{cal}$, de forma distinta a lo que podríamos denominar régimen común ${ }^{15}$.

Dicha elección de nuestra Constitución, en cuanto al modelo y las atribuciones a asignar a la figura del Alcalde o del Presidente de la Diputación, resultaba, asimismo, fundamentalmente de competencia estatal. Efectivamente, nuestra Constitución, a diferencia de otros Estados Federales (Alemania o Estados Unidos, por ejemplo), no atribuye a las Comunidades Autónomas las decisiones básicas sobre el sistema organizativo local (SSTC de 28 de julio de 1981 y de 21 de diciembre de 1989) ${ }^{16}$, aunque ello no quiera decir que éstas no tengan ningún ámbito de decisión en este campo dado el carácter bifronte del régimen local y el carácter del municipio como pieza integrante del Estado, pero también, y al mismo tiempo, elemento o componente de la estructura de la respectiva Comunidad Autónoma ${ }^{17}$.

Incluso es clara la competencia propia de los entes locales en este aspecto como componente innato de la autonomía local (STC de 21 de diciembre de 1989 y STS de 18 de julio de 1988, Ar. 5908) que, sin embargo, ha de moverse en el marco constitucional y legal, es decir, no es plena pero es de necesaria existencia ${ }^{18}$. Limitada, habremos de añadir nosotros ${ }^{19}$, en lo que atañe a los órganos básicos (Alcalde, Presidente en el

15 La forma de elección de los Diputados provinciales viene recogida en los artículos 202 y ss. de la Ley 5/1985, de 19 de junio, de Régimen Electoral General. Ahora bien, dicho régimen se singulariza en los casos más arriba expuestos.

${ }^{16}$ Que expresamente establecen que «Las comunidades locales no pueden ser dejadas en lo que toca a la... configuración de sus órganos de gobierno a la interpretación que cada Comunidad Autónoma pueda hacer de ese derecho a la autonomía constitucionalmente garantizada... La garantía constitucional es de carácter general y configuradora de un modelo de Estado y ello conduce como consecuencia obligada a entender que corresponde al mismo la fijación de principios o criterios básicos en materia de organización y competencias de aplicación general en todo el Estado».

17 Véase, en este sentido, J. L. DE LA VALLINA VALVERDE, «Potestad organizatoria y autonomía local», REALA n. ${ }^{\circ} 255-256,1992$, pp. 517 y ss. Lo que, a su vez, constituye un elemento decisivo en el reforzamiento de la figura del órgano unipersonal, en la medida en que en las materias sobre las que éstas ejercen sus competencias subyace un evidente interés local y el diseño realizado por la LRBRL atribuye al Alcalde y al Presidente de la Diputación la competencia residual para el ejercicio de aquellas competencias que no estén asignadas expresamente a ningún órgano municipal o provincial y sean delegadas por el Estado o las CC.AA. al Municipio o la Provincia. Dicha posibilidad expansiva es también apuntada por L. ORTEGA, «El Alcalde como...», op. cit., pp. 48 y ss.

18 Puede verse en torno al alcance de dicha potestad, junto al trabajo anteriormente citado, L. Parejo Alfonso, «La potestad de autoorganización de la Administración Local», $D A \mathrm{n} .^{\circ} 228$, 1991 y, más recientemente, La potestad normativa local, Edit. Marcial Pons, Madrid, 1998; R. Martín Mateo, «El Gobierno municipal», REALA n. ${ }^{\circ} 227$; G. FernánDez FarReres, «La potestad local de autoorganización. Contenido y límites», Tratado de Derecho municipal I, Madrid, 1988.

19 A idéntica conclusión llega Fernández FarReres, op. cit., p. 745, quien advertia, con carácter previo a la STC 214/1989, que de seguirse ese esquema «es obvio que la potestad autoorganizatoria 
caso de las Diputaciones, Pleno y Comisión de Gobierno), no tanto en cuanto a los órganos complementarios (donde, sin embargo, ha sido excesivamente llamativa y notoria, con carácter general, la ausencia de ejercicio por parte de los Gobierno locales de su potestad de autoorganización) dada la densidad normativa que procedente del Estado y de las Comunidades Autónomas han de soportar éstos ${ }^{20}$.

Desde nuestro punto de vista, una solución más adecuada hubiera estado constituida por aquella en que la legislación estatal hubiese visto reducida su capacidad de incidencia normativa respecto de los órganos básicos, aumentándose paralelamente la capacidad de diseño propio en el ámbito territorial de la Comunidad Autónoma y, consiguientemente, liberando espacio normativo para el ejercicio de la potestad de autoorganización por parte de los entes locales ${ }^{21}$. Dicha solución, además, sin perjuicio en absoluto de la identificación de las entidades en el conjunto del Estado, hubiese posibilitado en mayor medida el tratamiento no clónico de las entidades locales que, en el caso español, responden a realidades de población, territorio y funciones bien diferentes que aconsejan profun-

de las Entidades locales podría quedar radicalmente eliminada, completamente vaciada de contenido, colisionando así con el propio principio de autonomía local» y prácticamente el resto de los autores que se han ocupado del tema. Puede verse, a este respecto, C. Barrero Rodriguez, «El Reglamento Orgánico de las Entidades Locales en el sistema de fuentes», RAAP n. ${ }^{\circ}$ o M. J. SarmienTo AcostA, «La posición ordinamental de los Reglamentos Orgánicos de las Entidades Locales tras la STC 214/1989, de 21 de diciembre», REGAP n. ${ }^{\circ} 1$.

${ }^{20}$ Prácticamente ceñida, en cuanto a los órganos básicos, a cuestiones, sino menores, no excesivamente relevantes si las comparamos con su capacidad normativa en lo referente a los órganos complementarios. Verbigracia, decisión, en los municipios menores de 5.000 habitantes, sobre la existencia de Comisión de Gobierno (opción que también podía decidir un Acuerdo plenario), periodicidad de sesiones, funcionamiento de los grupos políticos, etc. Incluso es discutible la necesidad de que algunas de dichas cuestiones hubieran de ser objeto de la norma orgánica y no pudiesen se adoptadas por actos administrativos singulares. Puede verse, al respecto, el trabajo de E. SÁNCHEZ GOYANES, «La potestad normativa del municipio respecto al régimen de su organización y personal», $R E A L A$ n. $.273,1997$, pp. 162 y s.

${ }^{21}$ Dicha consideración se refuerza si observamos que en los grandes municipios (Madrid y Barcelona) la actualización de su régimen especial, en lo que hace referencia a su modelo organizativo, se encomienda a la Comunidad Autónoma mediante Ley, permitiéndose especialidades organizativas que afectan al régimen de organización y funcionamiento de los órganos básicos (Disposición Adicional sexta), tales como: modificación de la denominación de los órganos necesarios de los Ayuntamiento; posibilidad de que el Pleno funcione en base a Comisiones, pudiendo delegarse en ellas funciones que no exijan para su aprobación un quórum especial; posibilidad de atribución a la Comisión de Gobierno de materias no reservadas en exclusiva al Pleno, asi como las que se atribuyen al Alcalde en relación con el urbanismo, contratación, personal y adquisición y enajenación de bienes, y la aprobación de proyectos normativos locales y del presupuesto; y, por último, también se prevé que puedan atribuirsele al Alcalde, como propias, aquellas competencias que la Ley no reserva en exclusiva al Pleno. En el caso de Barcelona puede verse la Ley 22/1998, de 22 de diciembre, que aprueba la Carta Municipal de Barcelona y que configura un órgano ejecutivo desde una perspectiva más gerencial. 
dizar, sin perder de vista el esquema común, en los hechos organizativos diferenciales a todas luces existentes entre organizaciones cada vez más complejas (municipios con elevados presupuestos y población y Diputaciones provinciales) y la subsistencia, en forma paralela, de organizaciones más simples (municipios de escaso presupuesto y población) que seguramente aconsejan flexibilidad en el tratamiento organizativo.

Como ya se ha expuesto, el sistema elegido por la Ley $7 / 1985$, de 2 de abril, Reguladora de las Bases de Régimen Local, fue, en gran medida, la persistencia, si bien democratizándolo, del sistema preconstitucional existente al menos en cuanto a la copartición de las funciones de dirección y administración entre el Pleno y los órganos unipersonales (Alcalde en los municipios y Presidente en las Diputaciones Provinciales), con un fortalecimiento de los órganos unipersonales a los que se les dota de un carácter preferente y preeminente respecto de la gestión y administración del municipio en sus aspectos ejecutivos, que ha llevado a los distintos autores que se han ocupado del régimen local a hablar de un régimen presidencialista ${ }^{22}, y$, junto a ello, se les asigna la Presidencia del órgano deliberante y de control por excelencia, el Pleno. La pregunta inmediata surge, sin embargo, si nos preguntamos sobre si la persistencia del modelo establecido resulta adecuado o hubiese sido más adecuado una reflexión más amplia, a propósito de la reforma acontecida, en cuanto al conjunto de los órganos básicos de las entidades locales.

Y es que, como ha puesto de relieve JIMÉNEZ ASENSIO, el modelo finalmente resultante de la legislación local de 1985 importa técnicas e instrumentos de las diferentes formas de gobierno (presidencialista, parlamentaria o asamblearia), pero dificilmente admite en su seno la aplicación del principio de separación de poderes en lo que afecta a la distinción entre legislativo y ejecutivo ${ }^{23}$.

\footnotetext{
22 Véase, entre otros, F. Sosa WAGner, Manual de Derecho Local, Editorial Tecnos, Madrid, 1996, p. 73, y A. Ballesteros Fernández, Manual de Administración Local, Edit. Comares, cuarta edición, Granada, 1998, p. 93, que recoge, sin embargo, la jurisprudencia del Tribunal Supremo (SSTS 25 de octubre de 1989, Ar. 7.493, y 26 de junio de 1990, Ar. 5.223), que expresamente se refieren a que ese espíritu presidencialista «no debe llevarnos a la conclusión de aceptar un presidencialismo autoritario, desvinculado de las bases que componen los órganos de gobierno de estas entidades locales y reñido con el espíritu democrático sustentador del armazón de nuestro Estado de Derecho...», advirtiendo, como puede comprobarse, de las diferencias existentes entre el reforzamiento de la figura del Alcalde en la legislación de 1985 y la que existía en la legislación local franquista.

${ }^{23}$ R. JIMÉNEZ ASENSIO, «La forma de Gobierno Local: ¿Cambio o continuidad?, intervención desarrollada en el Taller sobre Autonomia Local del Congreso de la Asociación Española de Derecho Constitucional, celebrado en Alicante los días 28 y 29 de abril de 1999.
} 


\section{Les elementos de tensión y cambio para una perspectiva más gerencial de los órganos unipersonales existentes en el Gobierno local}

Los últimos veinte años han sido testigos de una profunda transformación de nuestros Gobiernos locales, que han mutado su consideración tradicional como entes sólo y exclusivamente administrativos en que los cuales las funciones de dirección y gestión político-administrativa se desempeñaban, al menos en gran parte, por altos funcionarios y en que el poder de los cargos de naturaleza política en éstos quedaba casi reducido, en muchos casos, meramente a funciones de representación. Puede decirse, con carácter general y con las matizaciones que sean necesarias, que la tecnocracia local desempeñaba un número importante de funciones y, al menos en este sentido, se producía una cierta usurpación, incluso con cierto respaldo legal, del espacio político que correspondía a las autoridades locales.

Dicha situación ha ido progresivamente, sin lugar a dudas, desapareciendo al paso que la democratización de la esfera política local se ha plasmado de forma incontrovertible y el acceso a los cargos públicos se ha ido realizando por las elites políticas que han reclamado para sí, lógicamente, un legítimo espacio de decisión, incluso, en algunos supuestos, con una usurpación a la vez, en esta ocasión de carácter inverso, del espacio que corresponde ocupar a la burocracia local confundiendo los que es la actividad en la política local con el Gobierno y la gestión local ${ }^{24}$. En realidad, esa dicotomía weberiana entre política y administración y esa radical, y en algunos casos, irreconciliable distinción entre los responsables políticos y los altos funcionarios locales también ha ido diluyéndose: de una parte, por la experiencia de gobierno adquirida en estos veinte años de gestión por los políticos locales; de otra, por las modernas tendencias de gestión pública - la nueva gestión pública en la terminología habitualmente utilizada - que aconseja la necesidad de desconcentrar la toma de decisiones en los directivos de línea y pone de relieve la necesidad de que, dada la complejidad creciente de las actividades públicas, los altos directivos se impliquen, sin merma de su imparcialidad, en la realización efectiva del proyecto político en ese momento sustentado y, a su vez, y a la inversa, que los responsables políticos decidan sus estrategias en función también de componentes técnicos ${ }^{25}$.

\footnotetext{
${ }^{24}$ Morell, op. cit., p. 434, habla de la existencia en el Gobierno local de un principio de separación entre el elemento político o representativo y el elemento burocrático.

${ }^{25}$ Los estudios realizados sobre el comportamiento de las elites burocráticas en los países occidentales (Alemania, Francia, Estados Unidos, Italia, etc.) ponen de relieve que éstas necesitan aunar sus conocimientos especializados con una lealtad y responsabilidad al proyecto político que sirven.
} 
Junto a ello, también es notorio el cambio producido en las funciones y en la consideración social de los entes locales, en la percepción que de su función tienen los ciudadanos, y en la que éstos han resultado claramente fortalecidos. En efecto, las políticas de reforma del Estado, basadas en la descentralización y en el acercamiento de la toma de decisiones al ciudadano; el principio de autonomía reconocido constitucionalmente a éstos y el principio de subsidiariedad como complementario a éste que busca afincar el ejercicio competencial en aquel escalón territorial más cercano al ciudadano apto para el cumplimiento idóneo de éstas; el hecho de que las políticas de desarrollo económico, en el marco de la globalización, busquen una localización territorial local y regional dejando el Estado de asumir el papel protagónico en las mismas y constituyendo fundamentalmente a las ciudades en los núcleos nodales de éstas, entre otras y variadas causas, han motivado una necesidad de, utilizando la expresión de OSBORNE, reinventar el Gobierno local, subrayando de forma más insistente su variable de gobierno y no de mera administración ${ }^{26}$.

Dichos cambios, de otro lado, se han operado en un diseño institucional del poder local en que las funciones de dirección y gestión era compartidas, con una cierta supervivencia del modelo preconstitucional ${ }^{27}$, entre el órgano colegiado de representación política, el Pleno, y el órgano

J. Aberbach, R. Putnam y B. Rockman, Bureaucrats and Politicians and Western Democracies, Harvard University Press, Massachusetts, 1981. De sumo interés resulta, en este sentido, el trabajo de F. MerLon, «La distinción entre política y administración», $D A$ n. ${ }^{\circ} 250-251$, pp. 365 y ss., donde el autor relata los avatares de la relación entre los dirigentes administrativos y los responsables políticos en el caso italiano con referencias de interés para la esfera local. Ciertamente, en el caso español, no se ha resuelto definitivamente la dicotomía apuntada, especialmente en el caso de los habilitados nacionales, por la dificultad de establecer un cuadro orgánico que, junto a respetar la autonomía organizativa de los entes locales, garantizase la profesionalidad de éstos como órgano de colaboración y garante de la legalidad de la acción administrativa. De ineludible consulta, en relación a la configuración gerencial, resulta el volumen colectivo Gobierno local y modelo gerencial, Editorial Fundación Carles Pi i Sunyer, Barcelona, 1999.

26 A. CALDERo CABRE, «Modelos de gobiemo municipal» y F. LONGo, «Sistema político y participación ciudadana en el gobierno local español», ambos trabajos publicados en el volumen colectivo Estudios sobre Gobiernos locales, Edit. CEMCI, Granada, 1998, destacan la necesidad de evolución de la organización del gobierno local atendiendo a la nueva configuración de éste en sus relaciones con la sociedad y en relación a las nuevas funciones asumidas por éstos en línea con las mantenidas en este trabajo. L. PARejo Alfonso, La potestad normativa local, Edit. Marcial Pons, Madrid, 1998, p. 78, insiste en que los artículos 140 y $141 \mathrm{CE}$ otorgan al Gobierno local la garantía de un espacio de decisión y de acción propias, de suerte que no se reduce éste a la condición de un mero nivel administrativo descentralizado de instancias superiores y su corporación representativa actúa no como órgano colegiado administrativo con capacidad normativa, sino como representación del pueblo local, dotado de legitimación democrática organizativo-institucional, funcional y personal directa.

27 No puede olvidarse, sin embargo, en este punto que la tendencia a profundizar en el carácter gerencial del Alcalde se inicia ya con la Ley de Bases de Régimen Local de 1945, que recogía, en cierto sentido (y decimos cierto, en la medida que llegaba a oponer dicho carácter al también perfil democrático al que debe obedecer la figura), la tendencia de ampliar las atribuciones administrativas del Alcalde. 
unipersonal de dirección y gestión, el Alcalde, y que, si bien había representado cierta utilidad en el pasado y presenta ciertas ventajas ${ }^{28}$, también mostraba ciertos inconvenientes de identificación de la responsabilidad política y de una cierta neutralización de una gestión eficiente en determinados campos de acción del Gobierno local. Como puede constatarse, dicha organización, si bien con alguna tradición en nuestro régimen local - con las necesarias matizaciones-, dista mucho de ser la que opera en otros niveles territoriales de gobiernos (Estado y Comunidades Autónomas) en que el órgano colegiado desempeña funciones clásicas (presupuestos, función normativa, control y fiscalización del ejecutivo...) sin responsabilidad alguna en las tareas ejecutivas ${ }^{29}$.

Las circunstancias ya referidas respecto del distinto contexto en que se desenvuelve el Gobierno local en la actualidad, y la propia experiencia acumulada durante los quince años de vigencia de la LRBRL, que mostraban una cierta disfuncionalidad en cuanto a la eficacia de la distribución de funciones entre el órgano unipersonal y el colegiado, obligaban a un replanteamiento de la configuración competencial de dichos órganos optando por la configuración de un órgano unipersonal más fuerte en sus capacidades ejecutivas, así como ponían de manifiesto la necesidad de racionalizar las relaciones entre éstos profundizando las relaciones de control entre el órgano deliberante y el ejecutivo.

En este sentido expresado, el Preámbulo de la Ley de reforma de la LRBRL resume dichas consideraciones aludiendo a que:

«En segundo lugar se lleva a cabo... una nueva distribución de competencias entre el Pleno y el Presidente de la Corporación a fin de solventar los problemas planteados al atribuirse en la actual regulación al Pleno funciones que tienen un carácter eminentemente ejecutivo y que es más lógico que sean competencia del Alcalde, en aras de una mayor eficacia en el funcionamiento del respectivo Ayuntamiento o Diputación. Como contrapartida, se clarifican las competencias del Pleno, se refuerzan las funciones de control por parte de éste mediante una

${ }^{28}$ Puede verse en este punto el trabajo de M. SANCHEZ MORÓN, «El sistema político local: fórmulas de gobierno y participación ciudadana», en Informe sobre el Gobierno Local, MAP y Fundació Carles Pí i Sunyer d'Estudis Autonomics i Locals, Madrid, 1992, pp. 289 y ss.

${ }^{29}$ L. Parejo Alfonso, La potestad normativa..., op. cit., p. 79, entiende que «Si se contempla la posición y función de los Parlamentos en los ordenamientos superiores a la luz del sentido organizativo así precisado para el principio de división de poderes, se impone la conclusión de que la posición y función de la asamblea representativa en el esquema de Gobierno local se asemeja esencialmente a las de aquellos. Pues la organización interna de dicho Gobierno descansa igualmente en la diferenciación básicamente de dos órganos - asamblea representativa y órgano ejecutivo- para la distribución competencial entre ellos, distribución que responde a la lógica reserva de la deliberación y la decisión (especialmente normativa) a la corporación representativa y la atribución de la ejecución al Alcalde o Presidente. Y tal diferenciación tiene por finalidad también la limitación y moderación del poder, por más que éste sea exclusivamente infralegal». 
mayor frecuencia de sus sesiones ordinarias y se establece el carácter preceptivo de los órganos de estudio, informe y seguimiento de la gestión del Alcalde o del Presidente y de sus órganos delegados en los Ayuntamientos de los Municipios con más de 5.000 habitantes y en las Diputaciones Provinciales».

Palabras, como vemos, expresivas de un criterio, a nuestro juicio, de madurez alcanzada en el ejercicio del Gobierno local tras la experiencia adquirida en estos últimos veinte años y que, lógicamente, aconsejaban suprimir las trabas para un funcionamiento lo más funcional posible, sin olvidar, claro está, la necesidad de garantizar la responsabilidad en el ejercicio de las funciones públicas habilitando los oportunos controles políticos. No obstante, desde nuestro punto de vista, y por las consideraciones ya expresadas anteriormente, nos parece insuficiente. Para decirlo de una vez, y sin más rodeo, se podía, y a nuestro juicio se debía, haber profundizado en mayor medida. Efectivamente, la variable de Gobierno local, que hoy resulta indudable en nuestros entes locales, y su necesidad de responder con resultados y políticas eficaces a las demandas que la gestión municipal y provincial presentan hubiese aconsejado, a mi juicio, la posibilidad de que el Alcalde y Presidente de la Diputación Provincial hubiesen tenido la posibilidad de configurar libremente su equipo de gobierno entre electos o no como ocurre en otros niveles de gobierno ${ }^{30}$.

De otro lado, también cabría apuntar la necesidad de reflexionar sobre la uniformidad en el tratamiento organizativo de los órganos necesarios de las entidades locales, tan sólo excepcionada en algunas especialidades organizativas derivadas de tradiciones históricas (Concejo Abierto) o en los casos de Madrid y Barcelona. En verdad, no es posible pensar que organizaciones locales tan diferentes admitan un tratamiento homogéneo y que las atribuciones de los órganos locales presenten los mismos rasgos y semejanzas. Las organización ha de responder al entorno social y económico también y mucho nos tememos que éste no es uniforme en todas las entidades locales de España. De esta forma, si la copartición de funciones ejecutivas entre el Alcalde y el Pleno puede ser adecuada en pequeños municipios, no parece serlo tanto en organizaciones políticas de mayor envergadura política y económica.

Obviamente, y sin perjuicio de dichas matizaciones que nos han llevado a afirmar su carácter de insuficiente, la reforma realizada en las atribu-

\footnotetext{
30 En el mismo sentido, F. Longo, op. cit., p. 71, quien indica como linea de reforma «La atribución al Alcalde investido por el Pleno $\longrightarrow$, en el supuesto de elección directa, por el cuerpo clectoralde la facultad de formar libremente el ejecutivo municipal, incorporando a las personas que considere más capaces de impulsar su programa de gobierno, trátese o no de electos locales, ya sea mediante su integración en la Comisión de Gobierno o por medio de delegaciones unipersonales, y situándolas al frente de las responsabilidades políticas sectoriales que corresponda».
} 
ciones de los órganos de gobierno locales ha de ser juzgada de forma positiva en la medida en que racionaliza, aclara y dota de mayor eficiencia a los procedimientos de actuación de nuestras entidades locales ${ }^{31}$.

\section{LOS ÓRGANOS UNIPERSONALES EN EL GOBIERNO LOCAL Y EN SU RELACIÓN CON OTROS ÓRGANOS}

La pérdida de su condición de órganos de carácter estatal, acontecida en forma definitiva con la aprobación de la LRBRL, junto a la nueva posición del municipio y de la provincia consagrada por la autonomía reconocida constitucionalmente que les dota del derecho de participación en cuantos asuntos les atañen, reordenaron el espacio organizativo local ${ }^{32}$. De esta forma, dos consecuencias previas pueden extraerse según expone ORTEGA: la primera, referida a la desaparición del control jurídico del Alcalde sobre los actos de los demás órganos de la Corporación derivada ya de las modificaciones introducidas en el régimen local por el RDLey - 3/1981 y el RD 1262/1981; la segunda, consistente en que el Ayuntamiento integra como organización el conjunto del poder público local y contiene la doble función representativa y ejecutiva, de la cual participan sus dos órganos principales, el Pleno y el Alcalde ${ }^{33}$. La reforma operada

\footnotetext{
${ }^{31}$ De la misma opinión es M. Ayuso Ruiz-Toledo, «El Pacto local en la Ley de Bases de Régimen Local: atribuciones del Alcalde y del Pleno municipal», Revista Valenciana D'estudis autonómics, n. ${ }^{\circ} 26,1999$, p. 260 , que indica que «Obviando planteamientos juridico-políticos, debemos centrarnos en el análisis jurídico-administrativo de la modificación y resaltar en este orden que se observa - junto a estos dos fines programáticos- un saludable interés en dotar de mayor eficacia a la gestión municipal y al propio tiempo soslayar cuestiones de procedimiento administrativo que habian planteado en la práctica municipal numerosos conflictos o impugnaciones jurisdiccionales por aspectos de difusa normación».
}

32 Una matización debe hacerse, sin embargo, al respecto desde nuestro punto de vista. Si efectivamente el Alcalde no es un órgano ligado a una supuesta unicidad del Poder ejecutivo, y con ello ligado en una posición pseudojerarquizada respecto de la Administración central, ello no quiere decir que el municipio no deba ser considerado desde su integración en el Estado como un órgano del Estado-nación y, en ese sentido, considerar al Alcalde como un órgano que representa de alguna manera al Estado, en su conjunto, en el término municipal.

33 Ortega, op. cit., p. 52, resume así dicha posición: «El municipio, en tanto que ordenamiento territorial, está dotado de personalidad jurídica. El Ayuntamiento, en tanto que organización del ordenamiento municipal, también está dotado de personalidad jurídica. Se produce, así, una doble entificación, la de contenido general del municipio y la de contenido especializado, en cuanto elemento-organización, del Ayuntamiento. A su vez, el Ayuntamiento es una persona jurídica de carácter corporativo basado en la representación política de sus miembros - los concejales-, con dos órganos de expresión: el Alcalde y el Pleno. Uno de estos órganos -el Alcalde-es representativo por la regla democrática de la mayoria, ostenta la presidencia del ente Ayuntamiento-Corporación, su representación exterior de carácter político-institucional y expresa hacia el exterior, en las materias a él atribuidas, la voluntad jurídica del Ayuntamiento-ente. Otro de los órganos -el Pleno- se define por la reunión colegiada de los miembros de la Corporación, es representativo por la regla democrática del pluralismo y expresa también hacia el exterior, según la distribución legal de competencias, la voluntad del Ayuntamiento-ente a través de su Presidente, cargo que, mediante la técnica de la unión personal, recae en el titular de la Alcaldia». 
en 1999 obliga a matizar, sin embargo, dichas conclusiones. Si, en efecto, cabe aceptar que el Ayuntamiento integra como organización el conjunto del poder público local, dicha posición que integra una triple función: representativa, normativa y de control y ejecutiva, no es predicable, al menos por igual, respecto de todos los órganos municipales. De esta forma, desde nuestro punto de vista, la profundización en su vertiente de Gobierno local de nuestras entidades locales ha llevado a una profundización o especialización en las funciones de los órganos de éste. Así, la función ejecutiva aparece, ahora más claramente, afincada en el órgano unipersonal de gobierno, mientras que las funciones deliberativas, normativas y de control se radican en el órgano colegiado. Incluso, desde nuestro punto de vista, más aún podía haberse profundizado en dicha distinción.

En efecto, admitiendo la diferencia existente entre la naturaleza representativa de la Administración local y la meramente vicarial de la Administración estatal o autonómica, ello no obsta a poder mantener que la reciente reforma ha profundizado en la distribución de funciones, derivada de la clásica división de poderes, entre el órgano unipersonal y el órgano colegiado. En efecto, la subsistencia en el ámbito del órgano colegiado de ciertas funciones que pudiesen tener una consideración pseudoejecutiva no nos puede llevar sin más a una conclusión que mantenga que, en la actualidad, existe un reparto de funciones normativas y ejecutivas entre el Pleno, de un lado, y el Alcalde o Presidente de la Diputación, por otro. Pues, en efecto, aun cuando determinadas actuaciones del gobierno municipal/provincial requieren el previo acuerdo del Pleno - aún más limitadas tras la reforma-, la tarea propiamente de ejecución, tanto previa, como preparación de asuntos que serán objeto de acuerdo, como a posteriori, recae en el órgano unipersonal como órgano al que se encomienda la dirección del Gobierno y Administración municipal/provincial y la de publicación y ejecución de los acuerdos adoptados por el órgano colegiado.

Por otra parte, y como ha puesto de relieve PAREJO ALFONSO, el esquema del principio de división de poderes debe ser reinterpretado en el sentido de que el mismo implica, más que una separación estricta, una fragmentación en el ejercicio del poder. Es decir, que no se afinquen de forma absoluta en un solo poder dos o más facultades (normativa, ejecutiva, etcétera), pero no que dicha inicial conclusión nos lleve a extraer como consecuencia la imposibilidad por parte del órgano normativo y de control de ejercer funciones que, en cierto sentido, puedan calificarse como ejecutivas y viceversa. De esta forma, la jurisprudencia de nuestro Tribunal Constitucional (STC 86/1991, de 25 de abril) ha admitido que la fun- 
ción ejecutiva alude a una actividad específica que puede tener manifestaciones normativas ${ }^{34}$.

Incluso, a nuestro juicio, hubiese sido deseable haber establecido la posibilidad, ya apuntada más arriba, a concretar en el correspondiente Reglamento Orgánico, de delegación de competencias de éste no sólo en miembros de la Corporación, sino también, y así lo avalaría una concepción más gerencial del ejecutivo local en determinadas áreas de gobierno, en funcionarios directivos de los Gobiernos locales. La previsión constitucional de que el gobierno y administración del Ayuntamiento corresponde a Alcalde y Concejales no imposibilita, a nuestro juicio, tal conclusión. Es más, el tiempo se ha encargado de demostrar, en los hechos, que la visión mantenida por las leyes de función pública y de régimen local, en el sentido de imposibilitar a los funcionarios públicos la toma de decisiones que vinculen a terceros, ha sido errónea y poco práctica en el terreno del funcionamiento diario de los órganos locales ${ }^{35}$. Sin duda, además, ello coadyuvaría a que los miembros integrantes del órgano colegiado realizasen más plenamente sus funciones normativas y de control y fiscalización de la acción ejecutiva.

Nada obsta tampoco a dichas conclusiones las funciones, de las que ahora nos ocuparemos, que el Alcalde desempeña respecto del Pleno y de otros órganos colegiados que no son sino la expresión, ya referida más arriba, del carácter representativo y no meramente vicarial de la Administración local frente a otras Administraciones y de la integración de funciones característica de este escalón de gobierno. Obviamente, y en conexión con las opiniones ya adelantadas, desde mi punto de vista, hubiese sido deseable y de mayor coherencia la opción por una elección directa del Alcalde y que las funciones de Presidencia del órgano colegiado no hubiesen recaído en éste. Parece obvio, en este sentido, que muchos de los problemas que plantea la convocatoria de sesiones en la esfera local y la labor de control del Pleno sobre el órgano unipersonal se hubiesen visto facilitadas.

\footnotetext{
${ }^{34}$ L. Parejo Alfonso, «¿Existe una reserva constitucional de ejecución? Apuntes para la individualización de la función ejecutiva en el orden de las funciones estatales», Cuadernos de Derecho Público, n. ${ }^{\circ} 1,1997$.

${ }^{35}$ En efecto, la hipótesis mantenida por dicha legislación de reservar a los representantes políticos la toma de decisiones hacia el exterior, si bien podía tener cierta justificación en un determinado momento derivada de la eventual usurpación de responsabilidades de éstos por aquéllos, ni ha resultado eficaz, ni es coherente con un modelo de carrera administrativa que prime la responsabilidad en las tareas directivas y, en la práctica, ha determinado la superposición de representantes políticos y de gerentes conocedores del área de gestión. Una revisión de este paradigma, aún subsistente, creo que ayudaría a clarificar la funciones entre el estamento politico y funcionarial y haria posible la subsistencia de una carrera administrativa.
} 
De otro lado, estimo que no cabe establecer una posición relativa de superioridad de un órgano municipal —en concreto de Pleno y Alcaldecon respecto a otro. Si en efecto, como indica ORTEGA, el Pleno ostenta la potestad normativa, las tareas de control y fiscalización y su acuerdo es previo y necesario para la ejecución de determinadas actividades municipales, ello no nos lleva a la conclusión necesaria de que éste sea el órgano supremo de gobierno y administración municipal ${ }^{36}$. Aun siendo cierto que no se puede trasladar sin más, en la situación actual, el esquema de relaciones de Gobierno y Parlamento a la organización municipal, no es menos cierto que, por las consideraciones ya realizadas, amén del resto que veremos al analizar las atribuciones de la Alcaldía ${ }^{37}$, estimo que no puede hablarse de una superioridad de un órgano frente a otro cuando nos referimos a las funciones que desempeñan cada uno. Otra cosa serán las consideraciones que se deriven de la consideración de elección de primer grado que ostentan los miembros del Pleno y de la elección del Alcalde por éstos. Pero si nos referimos exclusivamente a las funciones que desempeñan, no tendremos sino que concluir que simplemente se trata de funciones distintas que desempeña cada órgano derivadas de su naturaleza de órgano colegiado y unipersonal en cada uno de los supuestos, cuyo análisis revela, en todo caso, una opción de la legislación local por propiciar un funcionamiento eficiente atribuyendo al órgano unipersonal las competencias de gestión y ejecución y estableciendo un equilibrio de éstas en el órgano colegiado mediante la potenciación de las funciones de control y fiscalización a posteriori como atribuciones más propias de éste.

En este sentido, y con sus singularidades propias, se profundiza, aun antes de la reforma, pero sin duda decisivamente tras ésta en la esfera local el esquema de división de poderes existente a nivel estatal con las matizaciones ya apuntadas ${ }^{38}$.

\footnotetext{
36 De idéntica opinión, subrayando este carácter de superioridad institucional del Pleno, se muestra MerCadal VIDaL, «Organización municipal», en el volumen colectivo Tratado de Derecho Municipal, Edit. Civitas, Madrid, 1988, vol. I, p. 891.

${ }^{37}$ Derivadas de su condición de su doble condición de Presidente del Ayuntamiento y del Pleno.

38 A juicio de J. A. Santamaría Pastor, Fundamentos de Derecho Administrativo, Edit. Ramón Areces, Madrid, 1988, pp. 1141-1142, «trazar un paralelo exacto sería, no obstante, exagerado; no hay, en sentido estricto, división de poderes en el seno del Ayuntamiento, en el que el Pleno sigue ostentando numerosas potestades tipicamente administrativas (el Pleno es también, pues, un órgano de gestión administrativa); tampoco hay una división del poder normativo en dos niveles subordinados entre sí, como en la esfera estatal (ley y reglamento), por cuanto el Pleno conserva el monopolio de esa potestad. En lo demás, sin embargo, las similitudes son cada vez más acusadas: el Ayuntamiento, por ejemplo, no es ajeno al fenómeno general de liderazgo de los ejecutivos monocráticos, cuyas competencias tienden a acrecentarse en perjuicio de los órganos colegiados de control».
} 
Realizadas estas consideraciones procederemos al análisis de las atribuciones de éstos. De forma previa, sin embargo, conviene hacer unas advertencias preliminares.

La primera, referida a que ha sido tradicional, al referirse a estos órganos unipersonales de Gobierno, realizar una clasificación de sus atribuciones en función de una triple condición que operaba en los mismos: Presidente del Ayuntamiento/Diputación, Jefe de la Administración municipal o provincial y Delegado del Gobierno. Como ya sabemos, esta última, con el reconocimiento constitucional de la autonomía local, ha devenido, lógicamente, como impropia y no puede considerarse totalmente subsistente, por lo que al referirnos a las atribuciones concretas de éstos pueden clasificarse, en la actualidad, en tres grandes bloques: como Presidente del Ayuntamiento o Diputación, como órgano que ostenta la dirección superior de la Administración municipal o provincial y como Presidente de los órganos municipales o provinciales ${ }^{39}$. En cualquier caso, la inclusión de determinadas atribuciones en uno u otro bloque no está exenta de problemática derivada de esa naturaleza, un tanto confusa, que ofrecen los órganos unipersonales dada la triple configuración aludida y las observaciones ya realizadas ${ }^{40}$.

La segunda, más sutil que la anterior, consistente en lo que podríamos denominar el pesimismo antropomórfico, a la manera de San Agustín, existente en la configuración de una gran parte de las competencias atribuidas a los órganos del Gobierno local e, incluso, podría decirse con ca-

${ }^{39}$ Clasificación utilizada por ORTEGA para referirse a las atribuciones de la Alcaldía y que vamos a seguir en la presente exposición.

${ }^{40}$ L. Morell Ocaña, op. cit., p. 566, sostiene que la legislación de régimen local de 1985 ha pretendido simplificar la sostenida caracterización del Alcalde. Señala dicho autor que «Ahora, el artículo 21.1 se limita a expresar que el Alcalde es el Presidente de la Corporación. En ese rasgo sitúa, a continuación, las atribuciones que antes se asignaban a los dos primeros trazos definitorios - Presidente del Ayuntamiento y Jefe de la Administración Municipal-, omitiendo toda referencia a la investidura como Delegado del Gobierno. La diferencia en el planteamiento formal pone de relieve el cambio en la concepción leal del propio Ayuntamiento. Según se expresó ya, el TR de 1955 parte de una estructura dual en cuanto al gobierno municipal: el gobierno y administración del municipio estarán a cargo del Alcalde y del Ayuntamiento, uno y otro con atribuciones propias (art. 58.1). Ciertas de esas atribuciones propias, en lo que concierne al Alcalde, son precisamente las que se desprenden de su condición de Jefe de la Administración municipal. Luego, en cuanto órgano distinto, preside el Ayuntamiento y, en su caso, la Comisión Permanente (art. 59). Lo que pone de relieve una identificación real entre Ayuntamiento y Ayuntamiento-Pleno que ahora, de acuerdo con la concepción constitucional, deshace el legislador ordinario. El Ayuntamiento es, en el Derecho vigente, la institución que se expresa jurídicamente en forma de Corporación; en ella, el Alcalde es uno de sus miembros, el que asume su presidencia. En tal concepto, la Ley le atribuye tanto la función de presidir los órganos colegiados de gobierno - Pleno y Comisión - como la jefatura del resto de la organización municipal; es decir, de la organización con que cuenta la Corporación». 
rácter general en la reforma realizada. Me explico. La lectura de éstas parece indicar dos redactores en las atribuciones. El primero, es el que se mueve en la esfera de lo deseable: la necesidad de dotar de más poderes al órgano unipersonal, el que pretende conseguir una mayor eficiencia en la gestión, etc. Es el legislador que realiza la primera parte de los parágrafos. Pero junto a éste hay un segundo legislador, el que no piensa en abstracto en la figura del órgano unipersonal, sino que, más bien, tiene presente la figura concreta de algunos Alcaldes y Concejales y su gestión al margen de cualquier consideración legal e, incluso, ética. Éste es el legislador que compone la segunda parte de cada parágrafo, que limita la atribución de dicho órgano unipersonal y que explica, a nuestro juicio, la razón y el porqué de que muchas atribuciones afincadas en los órganos ejecutivos de otros entes territoriales (relación de puestos de trabajo, por ejemplo) aparecen aquí residenciadas en el órgano colegiado representativo. De alguna forma, se produce aquí la discusión que JHERING apuntara en su trabajo El cielo de los conceptos jurídicos, la discusión sempiterna entre la realidad del ser y la idealidad del pensar ${ }^{41}$.

\section{LAS ATRIBUCIÓN DE COMPETENCIAS A LOS ÓRGANOS UNIPERSONALES EN CUANTO PRESIDENTES DEL ENTE PÚBLICO}

Básicamente, en cuanto a tal, corresponde al Alcalde-Presidente una función: representar al Ayuntamiento. Sin embargo, tal representación, y dadas las singularidades presentes en el Gobierno local, ha dado lugar a dos posiciones explicativas de la misma. Mientras MORELL y SANTAMARÍA mantienen que éste monopoliza la expresión ante terceros de la voluntad del Ayuntamiento ${ }^{42}$, ORTEGA estima, no obstante, que ésta es exclusivamente protocolaria y político-institucional, aunque con las importantes consecuencias que en materia de participación en órganos de colaboración y participación se derivan de ellas ${ }^{43}$. En cualquier caso, estimemos válida una u otra postura, de aceptarse la primera ciertamente lo que no puede desconocerse es que dicha representación para ser válida exige el previo acuerdo del órgano competente en aquellas materias atri-

${ }^{41}$ R. vON JHERING, Bromas y veras en la ciencia juridica, Edit. Civitas (Marginalia), Madrid, 1993, pp. 2.165 y ss.

42 L. Morell Ocaña, op. cit., p. 569, y J. A. Santamaría Pastor, op. cit., p. 1.141.

43 L. ORTEGA, op. cit., p. 54, explica que «el Alcalde es el Presidente del Ayuntamiento-ente, pero expresa la voluntad del mismo en base a la otra doble faz de la figura del Alcalde como órgano unipersonal y como Presidente de los demás órganos colegiados», lo que explicaria, a su juicio, la consideración de órganos del Pleno y del Alcalde. 
buidas a su esfera de actuación. Dicha posición ha sido, además, objeto de tratamiento cuidadoso en la reforma recientemente operada.

En efecto, como es conocido, la reforma local de 1945 hizo desaparecer la figura del Síndico que asumía la representación legal del Ayuntamiento, pero esta posición no ha quedado claramente afincada en el Alcalde/Presidente, que simplemente asume la exteriorización de la voluntad manifestada por el órgano colegiado en aquellas materias que son de su competencia. De esta forma, y por ejemplo, en actos que afectan a terceros, el Alcalde [arts. 21.1.k) y l)] y el Presidente [arts. 34.1.i) y j)] sólo ostentan la competencia para el ejercicio de acciones judiciales y administrativas en aquellas materias que son de su competencia aun cuando las hubiese delegado en otro órgano (sólo con carácter urgente, y posterior ratificación en la primera sesión que se celebre, en materias competencia del Pleno ${ }^{44}$ ) y la iniciativa para proponer al Pleno la declaración de lesividad en materias competencia de éstos ${ }^{45}$. Asimismo, le corresponde el planteamiento de los conflictos de jurisdicción con Juzgados y Tribunales, pero también, como en el supuesto anterior, previo acuerdo

44 La jurisprudencia de nuestros tribunales ha ido progresivamente, en base al principio pro actio$n e$, admitiendo la subsanación y convalidación de la actuación del Alcalde en el ejercicio de acciones judiciales cuando correspondía al Pleno. Así, si bien ha reiteradamente indicado que el Alcalde necesitaba Acuerdo del Pleno para comparecer ante los tribunales ya que no estaba legitimado como titular del órgano-Alcaldía (STS 5 de diciembre de 1991, Ar. 9.281), también ha señalado que, no obstante, cuando por otros hechos quede patente la voluntad corporativa se puede convalidar dicho ejercicio, admitiendo también la ratificación por el Pleno (STS de 8 de noviembre de 1996) e incluso declarando que dicho obstáculo no debe constituir un impedimento para el ejercicio de la acción, estando obligados los tribunales a ofrecer la oportuna subsanación (STS de 3 de febrero de 1998, Ar. 1.338). Si bien, también es cierto que, en determinados supuestos, nuestros tribunales han sido estrictos negándole postulación procesal para instar la revocación de la suspensión (STS 22 de diciembre de 1990, Ar. 10.418) o el allanamiento sin previo acuerdo plenario (STS de 19 de septiembre de 1997, Ar. 6.083). Sí se afirma, sin embargo, su capacidad para conferir poder de representación a procurador para pleitos subsistiendo, además, éste mientras no se revoque, aun cuando cambie la Corporación (STS de 8 de junio de 1990, Ar. 7.926).

De otro lado, en cuanto al concepto de urgencia, la jurisprudencia ha declarado que éste ha de matizarse en el sentido de limitar el ámbito de dicha facultad «a los casos en que la brevedad del plazo para ejercitar la acción haga razonablemente imposible o gravemente dificultoso que la decisión de acudir a los tribunales pueda adoptarse por el órgano al que la ley reserva normalmente la expresión de la voluntad de la entidad local dirigida a formular pretensiones judiciales» (STS 17 de abril de 1991, Ar. 3.223).

${ }^{45}$ En opinión de M. Ayuso Ruiz-Toledo, «El Pacto local en la Ley de Bases de Régimen Local. Atribuciones del Alcalde y del Pleno Municipal», Revista Valenciana D'Estudis Autonómics, n. ${ }^{\circ} 26,1999$, p. 245, tras esta atribución subyace la garantía de independencia del Alcalde en el ejercicio de las atribuciones que le son propias, de tal manera que, al reservarle la iniciación del procedimiento, se obsta una a modo de avocación por el Pleno de tales atribuciones por vía de su revisión. A nuestro juicio, sin embargo, y como en el caso del ejercicio de acciones judiciales, la declaración de lesividad en aquellos actos competencia de los órganos unipersonales debiera haber correspondido a éstos y no solamente la iniciativa. 
del Pleno ${ }^{46}$. Como puede verse, y respecto de la legislación anterior, se confiere al Alcalde/Presidente dicha atribución que antes le correspondía en exclusiva al Pleno y sólo en caso de urgencia al órgano unipersonal.

De otro lado, y aun cuando la práctica cotidiana o la inexistencia de mayoría absoluta puede desplazar al Pleno la competencia para el nombramiento de los representantes del Ayuntamiento en órganos externos, a nuestro juicio, dicha atribución corresponde sin duda alguna al Alcalde/Presidente, derivado de esta condición de representante del Ayuntamiento (art. 21.1.b) que es, precisamente, una competencia delegable ${ }^{47}$.

Dicha atribución comporta, además, la de presidir todos los actos públicos que se celebren en el término municipal, sin perjuicio de lo dispuesto en el Reglamento de Protocolo (art. 41.1 ROF) ${ }^{48}$ y, lógicamente, en su doble condición de Presidente del Ayuntamiento y del Pleno, le corresponde, como persona física, suscribir cualesquiera escrituras, documentos o pólizas (art. 41.12 ROF), pero esta última, como en los supuestos anteriores, precedidas, en su caso, de los acuerdos oportunamente adoptados por el órgano colegiado en materia de su competencia.

Pero, asimismo, como Presidente del ente público le vienen atribuidas una serie de funciones derivadas de esa condición entre las que podemos citar la convocatoria de consultas populares municipales, en los términos del artículo 71 LRBRL y la competencia para adoptar personalmente, y bajo su responsabilidad, en casos de catástrofe o de infortunios públicos $o$ grave riesgo de los mismos, las medidas necesarias y adecuadas, dando cuenta inmediata al Pleno [art. 21.1.m)] ${ }^{49}$.

\footnotetext{
${ }^{46}$ Como subraya Morell, p. 569, «es el órgano que asume, frente a los demás sujetos, la expresión de la voluntad de la Corporación, del Ente. Ahora bien, para que esa voluntad pueda válidamente manifestarse tiene que estar, en su caso, apoyada en el previo acuerdo del órgano - Pleno, Comisión o el propio Alcalde-, al que, por razón de la materia o asunto de que se trate, pertenece la competencia para adoptar la decisión».
}

47 A pesar de dicha aseveración, no conviene olvidar que alguna jurisprudencia (STS de 26 de abril de 1994) parece establecer que la designación de representantes del Ayuntamiento en órganos externos corresponde al Pleno por votación mayoritaria. No obstante, hay otra linea jurisprudencial que ha admitido dicha facultad, en concreto respecto de la designación de representantes en Cajas de Ahorro, en base a la competencia residual de éste (STS de 10 de noviembre de 1992, Ar. 8.664).

${ }^{48}$ A este respecto, es preciso tener presente lo dispuesto en el RD 2.099/1983, de 4 de agosto, que ordena la precedencia de las distintas autoridades concurrentes a un acto público.

49 Obsérvese que la utilización de los adjetivos «necesarias y adecuadas» implica que las mismas han de adoptarse con arreglo al principio de proporcionalidad. Repárese también que el TRRL no habla de «necesidad» sino de indispensabilidad de las medidas a adoptar, facultándolo a la directa ejecución de las obras, prestación de los servicios o realización de adquisiciones o suministros indispensables o contratarlos libremente, en todo o en parte, sin sujetarse a los requisitos formales le- 
De otro lado, la atribución de competencia residual le viene otorgada, a nuestro juicio, en virtud de esta consideración; competencia residual, por otra parte, que determina, incluso por encima de otro tipo de consideraciones, el calificativo de «presidencialista» que se ha otorgado a la organización de los entes locales dada la importante vis atractiva que la misma representa respecto de la legislación sectorial. A pesar del criterio de la ponencia en el debate de la LRBRL que aludió a la escasa trascendencia de la medida, la realidad práctica y legislativa demuestra que ésta resulta ser la más importante cláusula de atribución competencial a los órganos unipersonales y, como ha puesto de relieve GUIRADO CID, la enumeración de las materias que implica «desborda cualquier intento de recopilación»" ${ }^{50}$. La explicación de dicho resultado radica, a nuestro juicio, en el papel reservado al municipio en el contexto competencial de las organizaciones territoriales, al venir éste configurado, en mayor medida, como un ente de ejecución de políticas estatales o autonómicas en dichas normas sectoriales lo que determina que el órgano más adecuado para ejercerlas resulte finalmente, por la naturaleza habitual de éstas, ser el órgano unipersonal.

\section{LAS ATRIBUCIONES DE LOS ÓRGANOS UNIPERSONALES EN CUANTO PRESIDENTES DE LOS ÓRGANOS COLEGIADOS}

En el modelo orgánico establecido por la legislación de régimen local y electoral el Alcalde, en su condición previa de concejal, es miembro de la Corporación. Y un dato más es Presidente de la Corporación, y con ello de todos los órganos colegiados, ex lege. La elección del Alcalde lleva conexa la condición de Presidente del órgano colegiado. Nótese, sin em-

galmente establecidos. Autorizando simultáneamente el libramiento de los fondos precisos para hacer frente a los gastos con el carácter de «a justifican», sin perjuicio de instruir el oportuno expediente de modificación de créditos, cuando fuere necesario (art. 117 TRRL).

La jurisprudencia de nuestros tribunales ha aceptado frecuentemente dicho parágrafo para justificar la actuación de la Alcaldia. Así, por ejemplo, autorizándole a prohibir la extracción de aguas que ponen en peligro grave el suministro en tiempo de sequía, aunque fuese una convicción errónea, e indicando además que su no comunicación al Pleno es una simple irregularidad no invalidante (STS de 19 de diciembre de 1991, Ar. 351) o facultándole a la clausura de pozos de abastecimiento de agua a instalaciones turísticas por razones de salubridad pública, en base a su potestad de control de los servicios municipales (STS 24 de febrero de 1992, Ar. 2.780), o autorizando el secuestro de un contrato en materia de recogida de basuras, siempre que el mismo sea provisional hasta tanto se acuerde por el Pleno en la medida en que a éste le compete decidir las formas de gestión de los servicios y sus modificaciones (STS de 23 de septiembre de 1991, Ar. 6.868).

50 C. Guirado CID, El Alcalde en la legislación española, Edit. Trivium, Madrid, 1991, p. 387, quien pone de relieve que las normas sectoriales se refieren al municipio en general o al Alcalde en su condición de órgano monocrático. Así lo avala también la tradición. 
bargo, que de las previsiones constitucionales no es exigible dicha condición y perfectamente podría haberse optado por otro modelo en que la elección directa del Alcalde y su configuración orgánica separada permitiese la elección paralela de un miembro del órgano colegiado como Presidente del mismo ${ }^{51}$.

En su calidad de Presidente de todos los órganos colegiados ostenta otro conjunto de prerrogativas:

1. Convocar y presidir las sesiones del Pleno, Comisión de Gobierno y de cualesquiera otros órganos municipales.

- Convocatoria de sesiones ordinarias y extraordinarias (art. 80.1 ROF) con la periodicidad y demás limitaciones establecidas en la legislación local y electoral general 52 .

— Fijación del orden del día (art. 81.2 ROF), pudiendo alterar el orden de los temas, o retirar un asunto cuando su aprobación exigiera una mayoría especial y ésta no pudiera obtenerse en el momento previsto inicialmente en el orden del día (art. 91.3 ROF). Asimismo, en las sesiones ordinarias, y al finalizar el. examen de los puntos incluidos en el orden del día, somete-

51 En el mismo sentido, Morell, op. cit., p. 586.

52 Dichas facultades son exclusivas en el caso de la Comisión de Gobierno (art. 112 ROF). A las sesiones de la Comisión de Gobierno, por lo demás, le son aplicables las reglas que rigen para el Pleno con las especialidades establecidas en el artículo 113 ROF. Dicha facultad del Alcalde está cone$x a$ al derecho de participación en los asuntos públicos de los miembros de los órganos colegiados (art. 23.2 CE), de esta forma, la convocatoria de las correspondientes sesiones periódicas ha de realizarse preceptivamente, aun en el supuesto de que en opinión del Alcalde no haya asuntos de qué tratar (STS de 5 de junio de 1987) o de que los asuntos no están ultimados en su tramitación o estudio (STS de 9 de junio de 1988) y en las extraordinarias siempre que se den los requisitos establecidos para la correspondiente convocatoria (STS de 5 de octubre de 1987), dado que se trata de una competencia reglada, en que es aplicable la propia doctrina de la Mesa del Congreso, en virtud de la cual no cabe rechazar por un juicio técnico valorativo la celebración si se cumplen los requisitos formales reglamentariamente establecidos (STJ Valencia de 16 de enero de 1998). Salvo la fijación de la fecha dentro del plazo establecido, que sí corresponde al órgano unipersonal sin que, por ello, admita valoraciones de dicho órgano sobre la banalidad de la cuestión o prácticas que, so pretexto de la cuestión ha sido ya debatida, desvirtúen o corrijan su aplicación (STS de 10 de diciembre de 1991). No obstante, en cuanto a la fijación de fecha han de respetarse los criterios legales establecidos y de esta forma los dos dias hábiles que han de mediar para la convocatoria de la sesión extraordinaria han de computarse a partir del siguiente hábil (STS de 20 de mayo de 1998, Ar. 4.481). Tampoco cabe que el Alcalde realice una convocatoria urgente, pero sin tiempo suficiente para que los concejales puedan efectivamente asistir (STS de 8 de octubre de 1986) o sin reunir los requisitos establecidos (STS de 20 de mayo de. 1998, Ar. 4.481).

Ahora bien, ese derecho de participación lo es sólo cuando se ejerce en relación a asuntos que sean competencia del Pleno (STS 16 de diciembre de 1986) y entre dentro del ámbito de competencias del municipio (SSTS de 8 de junio de 1987 y 3 de febrero de 1988), por lo que no se vulnera el mismo en otros supuestos. 
rá a los distintos grupos políticos la conveniencia eventual de incluir algún asunto en el orden del día por razones de urgencia (art. 91.4 ROF) ${ }^{53}$.

- Sometimiento a la cuestión de confianza y análisis de la gestión de la Comisión de Gobierno (art. 106 ROF).

- Necesaria asistencia para la válida constitución del órgano colegiado, salvo la excepción prevista en el artículo 46.2.a) si no convocase la sesión extraordinaria, en cuyo caso el mismo sería sustituido por quien legalmente le corresponda y, en forma alternativa, por el miembro de la Corporación de mayor edad.

- Interrupción de las sesiones, de forma discrecional («a su prudente arbitrio»), para permitir las deliberaciones de los grupos por separado sobre la cuestión debatida, o para descanso en los debates (art. 87.2 ROF) ${ }^{54}$.

- Orden de colocación en el salón de sesiones de los grupos políticos, oídos los portavoces, con preferencia para los grupos que hubiesen obtenido mayor representación (art. 89 ROF).

- Dirección de los debates (art. 94 ROF) y concreción de los términos de las votaciones y forma de emitir el voto con la proclamación del resultado (art. 98 ROF). Concesión de un turno de explicación de voto para los grupos que no hubiesen intervenido en el debate o que tras éste hubiesen cambiado el sentido de su voto (art. $103 \mathrm{ROF}$ ).

- Mantenimiento del orden en los debates, pudiendo expulsar al público asistente cuando impida el normal desarrollo de la sesión (art. 88.3 ROF) o de los propios corporativos tras tres llamadas al orden a éstos (art. 95 ROF) 55 .

\footnotetext{
${ }^{53}$ La posibilidad de exclusión de un asunto del orden del día ha sido reconocida, con carácter general, por nuestros tribunales (STS 14 de febrero de 1990). Como indica la STS 20 de marzo de 1989, dicha atribución es exclusiva dado que la configuración del orden del día no se integra entre los derechos políticos que derivan del artículo $23 \mathrm{CE}$ y, por ello, los concejales en minoría no pueden pretender la inclusión de determinados puntos en el orden del día. No obstante, la propia sentencia advierte que si las leyes o reglamentos establecen vías muy estrechas podría cuestionarse la constitucionalidad de los preceptos que así lo establecieran en detrimento del derecho de participación en los asuntos públicos.

${ }^{54}$ Obviamente, dichas facultades se enmarcan dentro del principio de unidad de acto que rige la celebración de sesiones por los órganos colegiados de las entidades locales.

5s Relacionada con esta facultad está su competencia para autorizar el uso de grabadoras a los miembros corporativos o sistemas megafónicos o de circuitos cerrados de televisión que no afecta a los profesionales de la información (SSTS 8 de noviembre de 1984 y 18 de diciembre de 1990). Más recientemente, la STS de 18 de junio de 1998, Ar. 4.771, que lo justifica en base a su facultades de policía en el desarrollo de las sesiones.
} 
2. Decidir con su voto de calidad los empates [art. 21.1.c)]; atribución ésta que ha sido, en concreto, una de las modificaciones efectuadas por la Ley 4/1999. Aunque ello no quiere decir que, obviamente, la misma no existiera anteriormente, si bien con carácter no básico, tanto en el TRRL como en el ROF.

3. Rúbrica del libro de actas para la validez de los acuerdos de la Corporación (art. 52.1 TRRL).

4. Facultad de solicitud de informes previos al Secretario y al Interventor, o de quienes legalmente les sustituyan, a la adopción de acuerdos por la Corporación.

5. Propuesta al Pleno de la configuración de las Comisiones Informativas permanentes que serán presididas por éste, salvo delegación en cualquier miembro de la Corporación, a propuesta de la propia Comisión, tras la correspondiente elección efectuada en su seno (art. 125 ROF) ${ }^{56}$.

6. Nombrar y cesar a los miembros de la Comisión de Gobierno cuando ésta exista.

Atribuciones, como puede comprobarse, amplias. Tan amplias respecto del órgano colegiado que, desde nuestro punto de vista, pueden comprometer las labores de fiscalización y control encomendadas a este último. En efecto, la complicada y laboriosa regulación de convocatoria de sesiones establecida en la reforma quizás sería innecesaria si la Presidencia del órgano colegiado no correspondiese al órgano unipersonal.

\footnotetext{
56 Su funcionamiento, amén de las reglas específicas contenidas en los artículos 134 y ss. ROF, responde al mismo régimen de funcionamiento del Pleno, por lo que el Presidente ostenta en éstas idénticas atribuciones. Respecto de la facultad contenida en dicho precepto, ha de advertirse sobre la proporcionalidad que han de guardar las Comisiones constituidas (SSTS 27 de enero de 1987, 29 de noviembre de 1990 y 15 de junio de 1992), para lo cual ha de integrarse al Presidente en el Grupo político al que pertenece (Sentencia de 12 de marzo de 1990 del Tribunal Superior de Justicia de Andalucía). También ha de hacerse referencia a que dicha representación corresponde a los concejales electos y no a las formaciones políticas en que han sido electos (STC 30/1993, de 25 de enero). La delegación de la Presidencia por el Alcalde exige, como requisito previo necesario, para ser ajustada a Derecho, la elección y propuesta de la propia Comisión (STS de 14 de abril de 1993, Ar. 2.625). No compete, obviamente según lo ya expresado, al Alcalde la creación de las Comisiones Informativas y su Decreto en este sentido no puede convalidarse por el Pleno, aunque sí se produce la conversión en una Propuesta al Pleno (STS 15 de enero de 1992, Ar. 599).
} 


\section{LAS ATRIBUCIONES DE LOS ÓRGANOS UNIPERSONALES COMO TITULARES DEL ÓRGANO DIRECTOR ADMINISTRATIVO Y GUBERNATIVO DEL MUNICIPIO Y DE LA PROVINCIA}

Las atribuciones de los órganos unipersonales del Gobierno local, sobre todo en lo que se refiere a las estrictamente administrativas o gubernativas, venían atribuidas en la legislación local postconstitucional en tres textos normativos: la Ley de Bases, el Texto Refundido de Régimen Local y el Reglamento de Organización y Funcionamiento de Régimen Local, a los que habrá que añadir, lógicamente, la legislación sectorial dictada en materias de competencia de las entidades locales ${ }^{57}$. En efecto, la comprensión del alcance y características de éstas era preciso hacerla poniendo en relación a dicho conjunto normativo y a la legislación sectorial dictada, pues, en efecto, en unas ocasiones por la propia imprecisión utilizada por la norma básica ${ }^{58}$, en otros supuestos por la desafortunada dicción utilizada en ésta y en las mayoría de los casos porque su verdadero alcance, dada la cláusula de atribución de competencia residual que se hacía a los órganos unipersonales, ha sido determinado por la legislación sectorial estatal y autonómica dictada obligaba a realizar una interpretación normativa de conjunto ${ }^{59}$.

La reforma operada en el esquema de distribución de competencias en el nuevo marco normativo ha intentado, en este sentido, junto al ya citado acentuamiento de la vertiente gerencial y ejecutiva de estos órganos, resolver algunos de los problemas interpretativos generados sobre el sentido de éstas en la Ley de Bases de 1985.

\footnotetext{
57 Dichas atribuciones vienen recogidas en los artículos 21 LRBRL, 24 TRRL y 41 ROF en el caso del Alcalde y los artículos 34 LRBRL, 29 de TRRL y 61 ROF. Sin embargo, y como ya se habrá podido comprobar en cuanto a las atribuciones de éstos como Presidentes de los órganos colegiados, la completa enumeración de éstas no se agota en dichos artículos y a lo largo de dichos textos legales pueden encontrarse otras muchas.
}

58 Que determina que su comprensión real no pueda realizarse sin una lectura conjunta del conjunto de atribuciones realizado a favor del Pleno. Una detallada y completa regulación de las atribuciones del Pleno en la legislación general y sectorial puede encontrarse en A. BALLESTEROS FERNÁNDEZ, Manual de..., op. cit., pp. 77 y ss.

$59 \mathrm{Ha}$ de señalarse, además, que la atribución competencial a éstos no diferia excesivamente de la realizada en la legislación de régimen local anterior a la reforma de 1985 y la principal novedad que se integra dentro de éstas deriva de la nueva arquitectura del Gobierno local establecida con la supresión de la Comisión Municipal Permanente y su sustitución por la Comisión de Gobierno, con la única función de asistencia al Presidente con lo que, dada la cláusula residual establecida a favor de los órganos unipersonales de gobierno, se reforzaba de forma natural la posición del Alcalde y Presidente de la Diputación. 
Nosotros, para el análisis de dichas atribuciones, nos ceñiremos básicamente a las previsiones contenidas en la legislación sobre régimen local de carácter estatal, sin perjuicio de referencias, que no pretenden ser exhaustivas, a la legislación sectorial estatal y autonómica en la materia.

\section{Facultades de organización administrativa y nombramiento}

Dentro de las mismas integramos las contenidas en el artículo 23.3 y 4 LRBRL, referidas tanto al nombramiento de Tenientes de Alcalde como de concejales/diputados delegados en las diversas áreas de gestión de la entidad local ${ }^{60}$. Aunque, asimismo, deben entenderse insertas en ésta la facultad de nombramiento de personal eventual, dada que su significación y trascendencia en la gestión de gobierno, al menos desde nuestro punto de vista, así lo aconsejan (art. 104.2 LRBRL).

De otro lado, en cuanto a facultades organizativas, el artículo 41.2 ROF y la Disposición Adicional cuarta atribuyen a éste la organización de los servicios administrativos, en el marco del Reglamento Orgánico y, ciertamente, cabe encuadrar aquí su capacidad para dictar circulares e instrucciones de servicio. No obstante, es preciso señalar las importantes limitaciones que dicha facultad tiene en la competencia plenaria relativa a la aprobación de las plantillas de personal y relación de puestos de trabajo, en la medida en que sobre todo esta última constituye un instrumento organizativo de primer orden en lo que se refiere a la estructura burocrática de la entidad local y que, junto a las atribuciones realizadas al Pleno en materia de creación de órganos desconcentrados y aprobación de las formas de gestión de los servicios, así como de las Ordenanzas regularoras de cada uno de ellos, limita en tal grado dichas atribuciones que prácticamente las hace vacías de contenido si salvamos su capacidad de nombramiento tanto de los anteriores cómo de los funcionarios que ocupen puestos de libre designación ${ }^{61}$. Cuestión, la de aprobación de las relaciones de puestos de trabajo por el órgano representativo, que merecería cierta reflexión, en la medida en que se impone al órgano de ejecución, Alcalde o Presidente, la estructura y organización de la burocracia

\footnotetext{
$60 \mathrm{Y}$, obviamente, también las que corresponden a órganos descentralizados o desconcentrados como los Distritos (STS 16 de enero de 1990, Ar. 7.926), aunque en estos casos con sujeción a lo dispuesto en el Reglamento Orgánico y normas autonómicas de aplicación.

${ }^{61}$ Ciertamente, las potestades de organización también se ven limitadas por el control de dicha actividad que no puede incurrir en arbitrariedad acudiendo a fórmulas genéricas, con falta de motivación, como las «necesidades del servicio» en materia de traslados de personal (STS de 14 de enero de 1995, Ar. 2.369).
} 
que éste ha de dirigir para la consecución de sus objetivos. Y ello por el órgano colegiado representativo en que el Alcalde o Presidente puede estar en minoría, con lo que resulta la paradoja de que lejos de una situación de equilibrio entre los dos órganos básicos de la esfera local nos podemos encontrar con que el Alcalde puede tener que enfrentar su gestión con la organización burocrática deseada por la oposición que, sin embargo, no gestiona ni, lo que es más importante, responde al electorado por ello.

De forma complementaria, y en cierto sentido reiterativa, se le asigna la organización de los servicios de Recaudación y Tesorería, sin perjuicio de la facultad del Pleno para aprobar las formas de gestión de los servicios (art. 41.19 ROF). Como en el caso general, del que éste no resulta sino ser un caso singular, junto a la limitación contenida expresamente habrían de añadirse las anteriormente expresadas.

\section{Facultades de dirección del Gobierno y Administración Municipal}

Obviamente, ha de entenderse dicha competencia como dirección superior $y$, aunque contenidas en otros epígrafes específicos, encuadrados en esta facultad podrían entenderse integradas a su vez todas las restantes [art. 21.1.a)]. Se pueden destacar las siguientes atribuciones:

a) Dirigir, inspeccionar e impulsar los servicios y obras municipales.

b) Desempeñar la jefatura superior de todo el personal de la Corporación.

c) Ejercer la jefatura de la Policía Municipal, así como el nombramiento y sanción de los funcionarios que usen armas.

d) Publicar, ejecutar y hacer cumplir los acuerdos del Ayuntamiento/Diputación ${ }^{62}$.

\footnotetext{
${ }^{62}$ Como puede observarse, la reforma de 1999 incluye dentro de las atribuciones del Alcalde/Presidente la de constituirlo en el órgano ejecutor de sus acuerdos, que no era expresa en la LRBRL (era, sin embargo, contemplada en el TRRL), para el caso del Alcalde, aunque sí para el Presidente de la Diputación con lo que se unifica en Ayuntamientos y Diputaciones dicha previsión. No así la de suspender sus acuerdos que si figuraba en la legislación de régimen local de 1955 junto a ésta [art. 116.b)]. Dicha modificación implica, pues, que el Alcalde no puede controlar la legalidad de los acuerdos adoptados y como miembro de dicho órgano colegiado podrá exclusivamente, en su caso, proceder a su impugnación (STS de 14 de julio de 1987). En este sentido, hay que diferenciar entre su competencia para hacer público un Edicto de ejecución de un acuerdo plenario, y considerar que éste ha adoptado el Acuerdo que correspondia al órgano colegiado. Asimismo, y sin perjui-
} 
e) Hacer cumplir las Ordenanzas y Reglamentos Municipales.

f) Resolver conflictos de atribuciones entre órganos municipales, cuando no estén atribuidos al Pleno (art. 222 ROF).

Pero dicha facultad, unida a la anteriormente enunciada como competencia residual, determinan una importante posición de este órgano municipal que, en definitiva, le otorga también la preparación con arreglo a ésta de todos los expedientes que posteriormente serán sometidos al órgano colegiado.

\section{Facultades de intervención en la actividad de los administrados}

En esta materia podemos entender incluidas las siguientes:

a) Dictar Bandos ${ }^{63}$.

cio de las funciones de fe pública atribuidas a los habilitados nacionales, el Alcalde está habilitado para emitir Informes que tengan una trascendencia externa (oposiciones o concursos) sobre datos obrantes en la Administración municipal (STJ Andalucía de 14 de octubre de 1996).

${ }^{63}$ Debe recordarse en este punto la reiterada jurisprudencia mantenida por nuestros tribunales en torno a la distinción entre Bandos, por un lado, y Reglamentos y Ordenanzas locales, por otro. Destacando la citada jurisprudencia cómo los Bandos no tienen, a sensu contrario, naturaleza de disposición administrativa de carácter general (SSTS 18 de octubre de 1983 y 30 de octubre de 1984) y, por supuesto, no pueden contradecir lo establecido en una Ordenanza Municipal (STS de 10 de mayo de 1991, Ar. 4.272) ni siquiera a través de un Decreto aunque así fuese sugerido por la Comunidad Autónoma (STS de 6 de junio de 1991, Ar. 4.988). La jurisprudencia, con carácter general, ha reconocido en éstos tres funciones: recordatorio del Derecho vigente; posibilidad de establecer obligaciones ya recogidas en otras normas; y desarrollo de actividades ejecutivas previstas en las Ordenanzas (STJ Navarra de 13 de junio de 1994) exigiendo su publicidad y destacando que no proceden en materia sancionadora. Ello, sin embargo, no excluye de forma absoluta el carácter normativo a los Bandos y recuérdese a este tenor lo ya expresado sobre lo que implica la función ejecutiva en la reiterpretación del contenido de cada una de las funciones estatales a las que ya aludimos con Parejo Alfonso. En este sentido, y afirmando el carácter normativo del Bando, pueden consultarse las SSTS de 13 de julio de 1987 y 9 de mayo de 1991. Cuestión más discutida, sin duda, es su consideración o no como disposición administrativa de carácter general. MORELl ha insistido en la posibilidad de éstos de innovación del ordenamiento jurídico, mientras otros autores, como por ejemplo EMBiD IRUjo, entienden que sólo puede otorgárseles carácter de acto administrativo de carácter general. En nuestra opinión, y de acuerdo con lo expuesto más arriba sobre la nueva consideración que ha de merecer la función ejecutiva y en general la división de poderes, habría que plantearse la posibilidad de que el órgano ejecutivo del Gobierno local pudiese dictar también, en materias de su competencia y fundamentalmente en cuestiones organizativas, disposiciones que tuviesen la condición de disposiciones administrativas de carácter general. En el mismo sentido, y abordando dicha problemática, puede consultarse S. FARRÉ Tous, «Los Bandos del Alcalde», REALA, n. ${ }^{\circ} 273,1997$, pp. 122 y ss. No obstante, la STS de 9 de mayo de 1991 (Ar. 4.247) admite la posibilidad en el Alcalde de un poder reglamentario a través de los Bandos. 
b) El otorgamiento de las licencias, salvo que las leyes sectoriales lo atribuyan expresamente al Pleno o a la Comisión de Gobierno ${ }^{64}$.

c) Sancionar las faltas de desobediencia a su autoridad o por infracción de las ordenanzas municipales, salvo en los casos en que tal facultad esté atribuida a otros órganos ${ }^{65}$.

d) Exigir a todos los obligados el exacto y diligente cumplimiento de los servicios o cargas de carácter público, tales como estadísticas, padrones, censos, bagajes, alojamientos y prestaciones personales y de transportes.

e) Ejercer la jefatura de la Policía Municipal y dirigir la policía urbana, rural, sanitaria, de subsistencia, de seguridad y circulación y de costumbres, publicando al efecto Bandos, Órdenes o circulares de instrucciones ${ }^{66}$.

\section{Facultades en materia de personal 67}

\section{La distribución de funciones realizadas en esta materia entre el Pleno y} los órganos unipersonales de gobierno ha venido a ser acentuada a favor

${ }^{64}$ Se subsanan con la presente redacción los equívocos, y la discordancia con lo dispuesto en el TRRL, que la anteriormente establecida había generado en la doctrina y la jurisprudencia. El artículo 41.9 ROF dispone a tales efectos que compete a éste la «concesión de licencias de apertura de establecimientos fabriles, industriales, o comerciales y de cualquiera otra índole, y de licencias de obras en general, salvo que las ordenanzas o las leyes sectoriales la atribuyan expresamente al Pleno o a la Comisión de Gobierno. En esta materia es muy relevante la competencia de los Alcaldes en materia de protección medioambiental y en materia de espectáculos públicos y actividades recreativas. En este sentido, tanto la legislación estatal y la autonómica dictada en la materia radican en éste las competencias para la concesión de licencias (STS 16 de abril de 1992, Ar. 3.834). Pero, obviamente, aparejada a esta potestad de concesión de licencias se anudan otras sobre la vida efectiva de la misma. Así, clausura de actividades sin licencia o retirada temporal de la misma (STS 22 de septiembre de 1993, Ar. 6.533), retirada de actividades provisionales (STS de 21 de septiembre de 1993, Ar. 6.539), etc.

${ }^{65}$ En general, la competencia sancionadora viene establecida por la legislación sectorial directamente al Alcalde o, en otros supuestos, no directamente, pero sí como consecuencia de la competencia residual. Así ha sido afirmado en materia de disciplina de mercado (STS de 22 de octubre de 1992, Ar. 8.100), en materia de espectáculos públicos y actividades recreativas, en materia de protección ambiental (STS de 19 de enero de 1996, Ar. 286) o en materia de consumo cuando exista la oportuna delegación del Pleno (STJ Madrid de 14 de mayo de 1998).

${ }^{66} \mathrm{Al}$ respecto, la STS de 14 de mayo de 1992 (Ar. 4.312) reconoce la potestad del Alcalde para establecer medidas correctoras de ruidos hasta límites tolerables, aunque no existan normas específicas en virtud de las competencias que le atribuyen las normas ambientales. Asimismo, la STS de 19 de enero de 1996 (Ar. 2.818) ha considerado que los entes locales no tienen competencia para intervenir empresas según lo dispuesto en el artículo $128 \mathrm{CE}$, pero si para asegurar servicios de primera necesidad, estando dicha materia reservada al Pleno.

${ }^{67}$ Como en el resto de supuestos anteriores, y los posteriores a este apartado, es preciso recordar que sólo se incluyen las más significativas y que la legislación de función pública (conectada en 
de los segundos por la modificación de la legislación básica operada en 1999. De esta forma, se reservan al Pleno las facultades relativas al establecimiento del esquema general retributivo y organizativo de la burocracia local, atribuyendo a los órganos unipersonales el desarrollo de la gestión de recursos humanos en el marco de ésta. La reforma es del todo punto coherente en este aspecto, no sólo por razones de agilidad y eficiencia que son evidentes, sino también porque las mismas no son sino la expresión competencial de la declaración de la Ley de que dichos órganos unipersonales ostentan la Jefatura Superior del Personal. No obstante, y como ya se apuntó más arriba al hablar de las facultades del Alcalde/Presidente en materia organizativa, la reforma podía haber sido más profunda en este punto y, más específicamente, en lo que se refiere a la aprobación de las relaciones de puestos de trabajo.

Se incluyen, de esta forma, en la actualidad como competencia del Alcalde/Presidente:

a) Jefatura Superior de todo el personal de la Corporación y, como hemos visto anteriormente, la directa de la Jefatura de la Policía Municipal ${ }^{68}$.

b) Nombramiento del personal al servicio de la Corporación ${ }^{69}$.

c) Aprobación de la Oferta de Empleo Público de acuerdo con el Presupuesto y la plantilla aprobados por el Pleno.

d) Aprobar las bases de las pruebas para la selección de personal y efectuar la convocatoria de las mismas ${ }^{70}$.

este caso a la competencia residual del Alcalde) determinarian una lista de atribuciones en este campo mucho más extensa.

${ }^{68}$ Obviamente, dicha competencia en el marco de la legislación general y, en especial, de la de función pública. Así, por ejemplo, no puede ordenar a la policía municipal realizar las funciones del Alguacil-Portero en las vacaciones de éste (STJ Extremadura de 28 de abril de 1997).

${ }^{69} \mathrm{Ha}$ de entenderse incluida, junto a los funcionarios de carrera, en ésta el nombramiento y cese del personal eventual (art. 104 LRBRL), la contratación del personal laboral y su asignación a los distintos puestos de trabajo de carácter laboral previstos en las correspondientes relaciones aprobadas por la Corporación de acuerdo con la legislación laboral [art. 41.14.c) ROF] y el nombramiento y cese del personal interino [art. 41.14.d) ROF]. Por supuesto, todo ello, en los términos establecidos en la legislación vigente. De esta forma la jurisprudencia ha admitido como válido el nombramiento provisional de cabos de la policía municipal hasta tanto se celebran los oportunos concursos en virtud de esta facultad y de la anteriormente referida (STS de 9 de diciembre de 1991, Ar. 9.367) o la designación de Secretario habilitado para una sesión de la Corporación ante la ausencia de alguien que legalmente sustituyese al Secretario de la Corporación (STS de 27 de febrero de 1997, Ar. 1.298).

70 Como es conocido, nuestros tribunales (Sentencia de 16 de mayo de 1998) negaban, con anterioridad a la reforma, competencia alguna a los órganos unipersonales, e incluso a la Comisión de Go- 
e) Aprobar las bases de los concursos para la provisión de los puestos de trabajo [parece que habría que entender incluida en ésta las convocatorias para la provisión de puestos de trabajo por libre designación y su resolución art. 41.14.b) ROF].

f) Distribución de las retribuciones complementarias que no sean fijas y periódicas.

g) Premios y recompensas a todo el personal de la Corporación.

h) Concesión de licencias, permisos y reducciones temporales de jornada.

i) Declaración de situaciones administrativas, así como la jubilación de todo el personal.

j) Imposición de sanciones, incluida la separación del servicio de los funcionarios de la Corporación y el despido del personal laboral ${ }^{71}$. Posibilita, además, dicha previsión en este punto la motivación del acto sancionador dadas las dificultades de la misma en un órgano colegiado que es expresión de distintas sensibilidades políticas ${ }^{72}$.

Lógicamente, igual que en el resto de materias de las que nos ocuparemos en los epígrafes posteriores, la legislación de función pública completaría el conjunto de materias sobre las que los órganos unipersonales, bien directamente o en virtud de su competencia residual, desempeñan en este aspecto su labor.

\section{Facultades en materia de gestión económico-financiera}

La escueta dicción utilizada en 1985 para definir la competencia de los órganos unipersonales en materia económico-financiera ha sido sustituida por una más acorde a las reales competencias que se le otorgan en las

bierno, para la aprobación de bases referidas a la selección de personal, aunque éste fuese de carácter temporal.

${ }^{71}$ Se entienden también incluida en ésta ordenar la instrucción de expedientes disciplinarios, nombrar instructor del mismo y suspender preventivamente a toda clase de personal [art. 150.1.2 TRRL y art. 41.14.e) ROF].

72 Así lo pone de relieve M. Ayuso Ruzz-Toledo, «El Pacto Local en la Ley de Bases de Régimen Local: atribuciones del Alcalde y del Pleno Municipal», Revista Valenciana d'Estudis Autonómics, n. $^{\circ} 26,1999$, p. 243, con cita de la STC 7/1998, de 3 de enero, donde se resalta la importancia de la motivación y la dificultad de ésta en un órgano colegiado. 
normas reguladoras de la hacienda local. Como en el caso anterior, se reserva al Pleno las grandes decisiones en materia presupuestaria y la definición del marco financiero y tributario de las entidades locales ${ }^{73}$, dejando a los órganos unipersonales la gestión concreta de los recursos económicos necesarios para el cumplimiento del programa de gobierno. A un punto sí debemos referirnos, y es que en la medida en que se produzcan dudas o contradicciones referidas exclusivamente a aspectos competenciales entre lo establecido en la LRBRL y la LRHL, las mismas han de resolverse a favor de la primera que es la norma, desde nuestro punto de vista, prevalente a efectos competenciales.

En cualquier caso, en este apartado concreto, es imprescindible, según lo expuesto, la referencia a la Ley de Haciendas Locales y a la legislación de desarrollo de la misma para determinar el alcance concreto de las competencias enumeradas ${ }^{74}$. Entre éstas, destacamos las siguientes:

a) Desarrollo de la gestión económica de acuerdo con el Presupuesto aprobado.

b) Formar los proyectos de Presupuestos con la antelación necesaria para que puedan ser aprobados por el Pleno dentro del plazo señalado ${ }^{75}$.

c) Disponer gastos dentro de los límites de su competencia y de acuerdo con lo previsto en las Bases de Ejecución del Presupuesto ${ }^{76}$.

d) Aprobar las facturas que correspondan al desarrollo normal del Presupuesto y que hubieran sido recibidas por los servicios de Intervención.

${ }^{73}$ La jurisprudencia ha sido reiterativa en materia de contribuciones especiales, incluidos los acuerdos de imposición y ordenación, ya sea en obras obligatorias o facultativas, con Ordenanza General o sin ella, significando que compete al Pleno y no es delegable en el Alcalde (SSTS de 24 de noviembre de 1997, Ar. 9.267 y 4 de diciembre de 1997, Ar. 9.288).

\footnotetext{
74 Asimismo, es preciso tener en cuenta la Ley 55/1999, de 29 de diciembre, que ha efectuado diversas matizaciones respecto de las competencias económicas y en materia de contratación, a la vez que establece idénticas atribuciones en el caso del Alcalde y Presidente de la Diputación.

75 Dicha materia ha sido desarrollada, amén de en la Ley Reguladora de las Haciendas Locales, en el RD 500/1990, de 20 de abril, en el que también se le asignan al Alcalde/Presidente determinadas facultades en materia de modificaciones presupuestarias.

${ }^{76}$ No obstante, dicha facultad debe estar reinterpretada de acuerdo con otras facultades del Alcalde y del Pleno. Así, la jurisprudencia ha negado que éste pueda acordar gastos dentro de su competencia cuando éstos se producen en el marco de un Convenio suscrito con otra institución en el que se establece que el Alcalde hace la propuesta y al Pleno la decisión definitiva (STS de 3 de noviembre de 1994, Ar. 664).
} 
e) Ordenar todos los pagos que se efectúen con fondos municipales.

f) Autorizar los documentos que impliquen formalización de ingresos en Depositaría.

g) Conservar en su poder una de las tres llaves del arca de caudales y asistir a los arqueos ordinarios y extraordinarios.

h) Concertar operaciones de crédito, con exclusión de las contempladas en el artículo 158.5 de la LRHL, siempre que aquéllas estén previstas en el presupuesto y su importe acumulado, dentro de cada ejercicio económico, no supere el 10 por 100 de sus recursos ordinarios ${ }^{77}$.

i) Operaciones de tesorería cuando el importe acumulado de las operaciones vivas en cada momento no supere el 15 por 100 de los ingresos corrientes liquidados en el ejercicio anterior.

j) Rendir cuentas y liquidar el Presupuesto.

\section{Facultades en materia de contratación}

Como en casos anteriores, se amplían las facultades del Alcalde/Presidente a fin de agilizar la gestión de la propia entidad para la ejecución de las obras y servicios de su competencia. En este sentido, se modifica la opción del legislador de la década de los ochenta (TRRL), sobre todo en lo que se refiere a los gastos plurianuales. Entre las atribuidas se pueden destacar las siguientes:

a) Presidir la mesa de contratación.

b) Las contrataciones y concesiones de toda clase cuando su importe no supere el 10 por 100 de los recursos ordinarios del Presupuesto y, en todo caso, los mil millones de pesetas, así como los contratos y concesio-

\footnotetext{
77 Es decir, operaciones en que su importe total anual no supere el 5 por 100 de los recursos por operaciones corrientes del Presupuesto de la Entidad, que la carga financiera total de la entidad, incluida la derivada de las operaciones proyectadas, no supere el 25 por 100 de los expresados recursos y que las operaciones queden canceladas antes de que se proceda a la renovación de la Corporación que las concierte; operaciones para las que se exige acuerdo de Pleno con el quórum establecido en el artículo 47.3 LRBRL. Obsérvese que el artículo 59 de la Ley 50/1998, de 30 de diciembre, que modifica el Capítulo séptimo del Título primero de la LRHL, establecía que el porcentaje acumulado no debería de superar el 10 por 100 de sus recursos corrientes liquidados en el ejercicio anterior lo que difiere de la dicción ahora ya establecida. La contradicción debe salvarse, desde nuestro punto de vista, a favor de la reforma realizada al tratarse de un tema competencial.
} 
nes plurianuales cuando su duración no sea superior a cuatro años en todo caso, y las plurianuales de duración inferior cuando su importe acumulado supere el porcentaje indicado, referido a los recursos ordinarios del Presupuesto del primer ejercicio, y en todo caso, cuando sea superior a la cuantía señalada ${ }^{78}$.

c) Aprobación de los Proyectos de obras y servicios cuando sea competente para su contratación o concesión y estén previstos en el Presupuesto ${ }^{79}$.

d) Cuando ostenta la calidad de órgano de contratación todas las facultades que al mismo se le asignan en la legislación reguladora de la contratación pública $\mathrm{y}$, por tanto, es competente para la aprobación del Pliego de Cláusulas particulares, la aprobación del expediente de contratación, la apertura del procedimiento de adjudicación, prórrogas ${ }^{80}$, la imposición de sanciones por incumplimiento y las facultades exorbitantes de interpretar, modificar y resolver el contrato ${ }^{81}$.

\section{Facultades en materia de urbanismo 82}

También han sido ampliadas en este aspecto las atribuciones de los órganos unipersonales, $y$, en este caso concreto, del Alcalde, dado que, por la materia de que se trata, las Diputaciones Provinciales no juegan sino un papel de asistencia y cooperación con respecto al ejercicio de las compe-

\footnotetext{
${ }^{78}$ Se salva con esta redacción los «olvidos» que el anterior texto contenía al referirse exclusivamente a las obras y los servicios y la discutible competencia en contratos plurianuales derivada del TRRL. El parágrafo ha sido modificado por la Ley 55/1999, de 29 de diciembre, introduciendo diversas matizaciones a las contrataciones de carácter plurianual.
}

79 Atribución coherente con las atribuciones realizadas a favor de los órganos unipersonales en materia contractual.

${ }^{80}$ STS de 3 de septiembre de 1994, Ar. 7.032.

${ }^{81}$ Incluso, como admite la STS de 23 de diciembre de 1994 (Ar. 10.269), cuando el Alcalde no es órgano de contratación, puede ostentar determinadas facultades cuando así le faculta el Pliego de Condiciones (por ejemplo, en materia de incumplimiento contractual). No obstante, la declaración de urgencia siempre corresponde al órgano contratante y la contratación de un servicio público, aun cuando por la cuantía pudiera quedar enclavada en la competencia del órgano unipersonal, si implica variación de la forma de gestión corresponde al Pleno (STS de 24 de abril de 1996, Ar. 5.473).

${ }^{82}$ Dichas facultades ya fueron incrementadas por el RD-Ley 5/1996, de 7 de junio, de Medidas Liberalizadoras en Materia de Suelo. En realidad, salvo las competencias en materia de aprobación de normas e instrumentos de planeamiento (salvo la que corresponde al Alcalde de exposición de trabajos preparatorios en el Avance de Planeamiento STS de 21 de enero de 1992, Ar. 761), el Alcalde en materia urbanística tiene una competencia atrayente (STS de 26 de junio de 1990, Ar. 5.223). 
tencias municipales. Ha de señalarse, también en este aspecto, la oportunidad y acierto de la reforma que evita demoras en la gestión urbanística, sobre todo si tenemos en cuenta el carácter indelegable que en la Ley $7 / 1985$ tenían muchas de las facultades que ahora se establecen como competencia del Alcalde.

En esta materia resultan atribuidas, en consecuencia, a la Alcaldía las siguientes competencias ${ }^{83}$ :

a) Aprobaciones de los instrumentos de planeamiento de desarrollo del planeamiento general no atribuidas expresamente al Pleno (aprobación inicial de Planes parciales, especiales y estudios de detalle).

b) Aprobación de los instrumentos de gestión urbanística ${ }^{84}$.

c) Aprobación inicial y definitiva de los Proyectos de Urbanización.

d) Otorgamiento de las licencias urbanísticas ${ }^{85}$.

${ }^{83}$ Obviamente, las atribuciones del Alcalde en materia urbanística no se agotan en las expuestas -aqui sólo aparecen recogidas las que derivan de la legislación de régimen local-y, con carácter general, la legislación urbanística asigna importantes facultades: en materia de ruina dado que al referirse la legislación genéricamente al Ayuntamiento corresponde al Alcalde por su competencia residual (SSTS 23 de septiembre de 1992, Ar. 6.975 y 22 de noviembre de 1993, Ar. 8.789); órdenes de ejecución urbanísticas y medidas para asegurar la interrupción de obras sin licencia, retirada de materiales y maquinaria (STS de 6 de mayo de 1992, Ar. 4.134); en cuanto a la protección de la legalidad urbanística, como es conocido, la legislación del 76 establecía que la competencia para requerir la legalización era del Alcalde y la demolición correspondía al Pleno y sólo cuando éste no la ejercia al Alcalde (SSTS de 13 de noviembre de 1996, Ar. 8.017 y 30 de junio de 1997, Ar. 5.388), así como la de suspensión de los efectos de una licencia por infracción grave y manifiesta (STS 16 de febrero de 1993, Ar. 532). Sin embargo, en el Texto Refundido de 1992 la suspensión y demolición correspondian al Alcalde, pero tras la Sentencia del Tribunal Constitucional sobre dicha legislación habría que volver a los criterios establecidos (STJ Galicia de 14 de mayo de 1998) que además puede delegarse (STJ Madrid de 20 de mayo de 1995); en el Registro de Solares y Edificación Forzosa tanto la inclusión de un solar (STS 26 de junio de 1990, Ar. 5.223) como requerir un proyecto de obras para la edificación competen al Alcalde (STJ Navarra de 6 de noviembre de 1996); sanciones urbanísticas, etc.

${ }^{84} \mathrm{Y}$, por tanto, incluidas en ésta la aprobación inicial y definitiva de Bases y Estatutos de Juntas de Compensación, constitución de Juntas de Compensación y Asociaciones de Cooperación y los Proyectos de Compensación, Reparcelación y Expropiación. Ciertamente, en el caso de expropiación, se plantea una duda sobre la competencia del órgano unipersonal sobre la del órgano colegiado.

${ }^{85} \mathrm{La}$ jurisprudencia ha insistido en que la concesión de licencias urbanísticas, tanto ordinarias como especiales (obras en Puertos), competen al Alcalde (STS de 17 de febrero de 1995, Ar. 1.059). 


\section{Facultades en materia de Patrimonio}

La reforma operada en 1999 incrementa las facultades de los órganos unipersonales que hasta ahora estaban reservadas al Pleno - aun cuando fueran susceptibles en muchos casos de delegación- sobre todo en lo que se refiere a la enajenación como en el caso de la adquisición de elementos patrimoniales [art. 22.1 LRBRL y art. 23.1.a) TRRL] ${ }^{86}$.

a) Adquisición de bienes y derechos cuando su valor no supere el 10 por 100 de los recursos ordinarios del presupuesto ni los 500 millones de pesetas ${ }^{87}$.

b) Enajenación, con los límites señalados para la adquisición, de bienes inmuebles cuando esté prevista en el Presupuesto y de bienes muebles, salvo los declarados de valor histórico o artístico, cuya enajenación no se encuentre prevista en el presupuesto.

\section{Facultades gubernativas}

La legislación sectorial atribuye en este punto numerosas competencias al municipio que, como ya sabemos por la naturaleza de las mismas

${ }^{86}$ Como en casos anteriores, la legislación de patrimonio de entidades locales incrementa las atribuciones del órgano unipersonal fundamentalmente en lo que se refiere a uso y aprovechamiento de los bienes de las entidades locales y las licencias que lo hacen posible, salvo en aquellos supuestos en que la competencia pertenece al Pleno por la cuantía en el caso de utilización privativa. En el resto de los supuestos la legislación de bienes de las entidades locales hace, con carácter general, una opción a favor del órgano colegiado: alteración de la calificación jurídica de los bienes, ejercicio de prerrogativas (reintegro posesorio, investigación, desahucio, deslinde, etc. SSTS 2 de julio de 1991, Ar. 5.973 y 28 de mayo de 1992, Ar. 4.450), aprobación del inventario de bienes, etc. No obstante, el ejercicio de determinadas prerrogativas a favor del Alcalde pudiera entenderse admisible acogido a aquellos supuestos en que el ejercicio de acciones administrativas es de carácter urgente y, por supuesto, el acto inicial del Alcalde ordenando el retiro de un cerramiento es admisible (STS de 1 de diciembre de 1993, Ar. 8.789), aunque posteriormente el acto definitivo corresponda al Pleno.

Asimismo, compete al Alcalde la orden de desalojo de unos bienes municipales al constituir un puro acto de ejecución, que encuentra su fundamento en su facultad de ejecutar los acuerdos, cuando hay otros anteriores del Pleno que extinguen la relación contractual (STS de 9 de octubre de 1997, Ar. 7.327).

${ }^{87}$ Nótese que, a diferencia con lo que ocurre con las competencias de éste en materia contractual, las facultades de los órganos colegiados para la adquisición de forma cuantitativa no alcanzan la cifra de mil millones de pesetas. No parece, en principio, ello congruente y la limitación no nos parece adecuada dado que no parece que existan razones procedimentales, ni incluso sustantivas por la materia, que así lo aconsejen.

La adquisición por vía expropiatoria está reservada al Pleno según la LEF, no estando habilitado el órgano unipersonal para llegar a un convenio verbal con los expropiados o cualquier otro acto del procedimiento expropiatorio que sea recurrible (STS de 30 de marzo de 1994, Ar. 1.904). 
(fundamentalmente actividades de policía), caen dentro de la esfera de ejercicio por parte del Alcalde ${ }^{88}$. En este sentido, tanto la Ley de Orden Público —en lo no derogado—, la Ley de Seguridad Ciudadana, la Ley de Protección Civil, la Ley sobre Tráfico, Circulación de Vehículos a Motor y Seguridad Vial, el Reglamento de Armas y otras normas complementarias o de desarrollo de éstas ${ }^{89}$, podemos decir que configuran al Alcalde como un sujeto protagónico en el ejercicio de competencias en esta materia que, por su naturaleza, exigen una participación destacada del municipio. En efecto, competencias tales como Jefe de la Junta Local de Seguridad, Jefe de Protección Civil en el término municipal, la competencia para la concesión de licencias de armas de determinadas categorías, la capacidad para la ordenación del tráfico y los transportes públicos de viajeros, las atribuciones en materia de incendios forestales, la facultad de sancionar en los aspectos contemplados en dichas normas, etc., podemos decir que atribuyen a la Alcaldía un papel importante en esa materia.

Incluso, las competencias en tales aspectos, como se sabe fundamentalmente de competencia preponderantemente estatal o autonómica, ponen en cuestión que éste no asuma, al menos parcialmente y con las matizaciones que se quiera, una condición equivalente a la de Delegado del Gobierno estatal o autonómico en el término municipal y su carácter, en este sentido, de autoridad (STS 14 de mayo de 1969). No puede olvidarse, como han puesto de relieve MORELl y CASTELAO, que muchas facultades de las antes enumeradas le eran atribuidas en virtud de dicha consideración ${ }^{90}$. Y si bien no puede afirmarse que subsista dicha consideración, al menos con el sentido y alcance que le era otorgado en la legislación anterior, sí que creo que puede mantenerse, y en la medida en que el municipio se inserta como elemento básico en la estructura territorial autonómica y estatal, que éste ostenta un cierto carácter representativo del Estado, como organización total, y de la Comunidad Autónoma en el término municipal.

\footnotetext{
${ }^{88}$ Un estudio detallado de éstas puede encontrarse en el estudio de C. Guirado CiD, El Alcalde en la legislación española, Edit. Trivium, Madrid, 1991. También puede consultarse, a este respecto, F. López-NiEto y Mallo, Manual del Alcalde, Edit. El Consultor de los Ayuntamientos y los Juzgados, Madrid, 1987.

${ }^{89}$ Normas tales como las relativas a materia medio ambiental, incendios, transportes de mercancías peligrosas, etc., complementan las competencias del Alcalde en esta materia.

90 L. Morell Ocaña, El Régimen local..., op. cit., p. 574 y Castelao Rodriguez, González Quinza y Villar EzCURRa en Régimen Local y Autonómico, Edit. Universitas, p. 182.
} 


\section{Supuestos de delegación de atribuciones 91}

Los supuestos de delegación de atribuciones han sido también objeto de reforma en coherencia con las modificaciones efectuadas en las atribuciones de éstos ${ }^{92}$. De esta forma, el artículo 21.3 y el artículo 34.2 establecen como indelegables la de convocar y presidir el Pleno y la Comisión de Gobierno y decidir los empates con voto de calidad, la concertación de las operaciones de crédito, la jefatura superior de todo el personal, la separación del servicio de los funcionarios y el despido del personal laboral. Asimismo, se contemplan como indelegables, para ambos, la dirección - se ha de entender superior- del gobierno y administración municipal, el ejercicio de acciones judiciales y administrativas en los términos ya expresados anteriormente y la iniciativa para la declaración de lesividad en materias de su competencia.

De forma específica, y sólo en el caso del Alcalde, no serán delegables, además de las enunciadas con anterioridad, las siguientes: dictar bandos; las relativas a aprobaciones de instrumentos de planeamiento y de gestión urbanística (que sí lo serán a favor de la Comisión de Gobierno); y, por último, la adopción de medidas extraordinarias en caso de catástrofes., infortunio público o grave riesgo de los mismos.

\section{CONCLUSIONES}

Como puede verse de lo expuesto, la configuración organizativa del Gobierno local en nuestro país ha sido sacudida en su evolución por diversos condicionantes históricos. Sin embargo, la actual posición de éste en el contexto del Estado obligan a una reflexión sobre el significado y alcance que ha de tener la planta organizativa y su necesaria reconfiguración, con sus características peculiares, pero con la mirada puesta hacia

\footnotetext{
${ }^{91}$ Los supuestos de delegación de atribuciones tienen una normativa específica, con unos requisitos establecidos, en el ROF. No obstante, la jurisprudencia ha establecido que los errores en la delegación cuando no sean manifiestos no constituyen vicio de nulidad (STJ Extremadura de 22 de septiembre de 1998), aunque es preciso que conste la delegación y se publique (STS de 11 de marzo de 1997, Ar. 1.670). Además, las mismas subsisten, aunque cambie el Alcalde, si no se revocan (STS de 13 de noviembre de 1996, Ar. 8.017). Caben también en miembros que no pertenecen a la Comisión de Gobierno siempre que consten por escrito, con forma de Decreto y sean publicadas en el BOP (STJ Valencia de 15 de mayo de 1998).

${ }^{92}$ Con carácter previo a la aprobación de la reforma de la normativa básica de régimen local ya había sido objeto de modificación el artículo 127 de la Ley 30/1992 por la Ley 4/1999, en virtud de la cual se removía el obstáculo que impedia la delegación de competencias (no la desconcentración en otros órganos mediante Bando que se publicase STJ Aragón de 6 de marzo de 1997) de los Alcaldes en materia sancionadora (SSTJ Cataluña de 22 de abril de 1997 y 16 de enero de 1998).
} 
un esquema de distribución de funciones más similar a otras instancias territoriales superiores.

Elementos tales como la capacidad normativa local, tanto del Pleno como de los órganos unipersonales, la diferenciación de funciones entre uno y otro, la necesidad de extraer las consecuencias necesarias en orden a la configuración de los equipos de gobierno, la posibilidad de elección directa, etc., son, sin lugar a dudas, puntos que aún no han sido absolutamente resueltos y que merecen una mayor reflexión; reflexión que, más allá de ciertos mitos y condicionantes políticos, parece ha de obedecer en mayor medida a la percepción que del Gobierno local tiene la sociedad, las exigencias que ésta plantea y los propios condicionantes constitucionales que para la acción de éste vienen establecidos. Asimismo, el esquema de organización básica no puede ni debe establecer un uniformismo organizativo que integra bajo su manto realidades organizativas diversas y hubiese sido más aconsejable, en este sentido, haber posibilitado una mayor participación de las CCAA en el desarrollo de las atribuciones del Alcalde/Presidente en coherencia con su estructura territorial y las realidades locales que existen en el territorio de cada una de éstas. 
REAL-1999, núm. 280-281. CASTILLO BLANCO, FEDERICO A.. LA CONFIGURACIÓN DE LOS Ó...

REAL-1999, núm. 280-281. CASTILLO BLANCO, FEDERICO A.. LA CONFIGURACIÓN DE LOS Ó... 